\title{
THE ECONOMETRICS AND ECONOMICS OF THE EMPLOYMENT EFFECTS OF MINIMUM WAGES: GETTING FROM KNOWN UNKNOWNS TO KNOWN KNOWNS
}

\author{
David Neumark \\ Working Paper 25043 \\ http://www.nber.org/papers/w25043 \\ NATIONAL BUREAU OF ECONOMIC RESEARCH \\ 1050 Massachusetts Avenue \\ Cambridge, MA 02138 \\ September 2018, Revised November 2018
}

This paper was given as the keynote address for the EVA-MIN conference "Evaluation of Minimum Wages" at DIW Berlin on July 4-5, 2018 and was prepared for the special issue on Minimum Wages in the German Economic Review. I am grateful to William Wascher for longstanding research collaboration, and to Jeff Clemens, Kyle Colangelo, Matthew Harding, Jonathan Meer, Joan Monras, David Powell, Carsten Schroeder, Evan Totty, and Weilong Zhang for helpful comments and discussions of this paper. Some of the material in this paper is covered, in much less detail, in Neumark (2018). The views expressed herein are those of the author and do not necessarily reflect the views of the National Bureau of Economic Research.

NBER working papers are circulated for discussion and comment purposes. They have not been peer-reviewed or been subject to the review by the NBER Board of Directors that accompanies official NBER publications.

(C) 2018 by David Neumark. All rights reserved. Short sections of text, not to exceed two paragraphs, may be quoted without explicit permission provided that full credit, including (C) notice, is given to the source. 
The Econometrics and Economics of the Employment Effects of Minimum Wages: Getting from Known Unknowns to Known Knowns

David Neumark

NBER Working Paper No. 25043

September 2018, Revised November 2018

JEL No. J23,J38

\begin{abstract}
I discuss the econometrics and the economics of past research on the effects of minimum wages on employment in the United States. My intent is to try to identify key questions raised in the recent literature, and some from the earlier literature, which I think hold the most promise for understanding the conflicting evidence and arriving at a more definitive answer about the employment effects of minimum wages. My secondary goal is to discuss how we can narrow the range of uncertainty about the likely effects of the large minimum wage increases becoming more prevalent in the United States. I discuss some insights from both theory and past evidence that may be informative about the effects of high minimum wages, and try to emphasize what research can be done now and in the near future to provide useful evidence to policymakers on the results of the coming high minimum wage experiment, whether in the United States or in other countries.
\end{abstract}

David Neumark

Department of Economics

University of California, Irvine

3151 Social Science Plaza

Irvine, CA 92697

and NBER

dneumark@uci.edu 


\section{Introduction}

The United States is embarking, in at least some regions, on an experiment of using high minimum wages to try to increase incomes of workers and to reduce poverty. Figure 1 shows state minimum wages as of Jan. 1, 2018. There are now 29 states (plus the District of Columbia) with minimum wages above the federal minimum wage, with an average difference across states of 30.2 percent. As a result, the federal minimum wage now provides a floor for an increasingly narrow set of states, concentrated in the South (see Figure 2). Moreover, California, Massachusetts, New York, Seattle, and Washington, DC have legislated either current or future minimum wages of \$15, other localities may follow, and a change in the national political alignment could result in a \$15 national minimum. ${ }^{1}$

Some economists claim with confidence that a \$15 minimum wage will not result in job loss (e.g., Reich, 2016). Others argue that a \$15 minimum wage will lead to huge job losses (e.g., Even and Macpherson, 2017). These divergent views are also reflected in the media. For example, conflicting titles in articles from Forbes and The American Prospect read, respectively, “A Statewide \$15 Minimum Wage is a Bad Idea,”2 and "Why a \$15 Minimum Wage is Good Economics.”3

I regard such confidence regarding the effects of a \$15 minimum wage as badly misplaced, for two reasons. First, although one might think that we know pretty much everything about the employment effects of minimum wages in the United States, given the scores of papers written, using ever-richer data and more-refined empirical techniques, the debate among researchers about whether minimum wages reduce employment, and if so by how much, remains intense and unsettled. Second, even if one has a strong view of what the U.S. literature says about the employment effects of past minimum wage increases, this may provide much less guidance in projecting the consequences of much larger minimum wage increases than those studied in the prior literature. ${ }^{4}$ Predicting the effects of minimum wage

\footnotetext{
${ }^{1}$ A $\$ 15$ federal minimum wage was part of the Democratic Party platform in the 2016 elections.

2 This was in reference to Virginia. See https://www.forbes.com/sites/adammillsap/2017/03/10/a-statewide-15minimum-wage-is-a-bad-idea/\#4817ea465d4a (viewed June 24, 2018).

${ }^{3}$ See http://prospect.org/article/why-15-minimum-wage-good-economics (viewed June 24, 2018).

${ }^{4}$ The past literature may also be less informative about the effects of minimum wages at a more limited geographic scale, such as cities. For example, there may be more scope for business relocation (or choosing alternative locations for new businesses) in response to a local minimum wage.
} 
increases of many dollars, based on research studying much smaller increases, is inherently risky for the usual statistical reasons. But the problem is potentially exacerbated because the reduced-form estimates on which the prior literature is based may fail to capture changes in underlying behavior as high minimum wages affect a far greater share of workers. ${ }^{5}$ The same issues carry over to large minimum wage increases elsewhere, such as the recent introduction of a minimum wage in Germany in 2015, starting at a relatively high 8.50 Euro.

My main goal in this paper is to delve into the econometrics and the economics of past research on the effects of minimum wages on employment in the United States. My intention is not to relitigate the debate about research on minimum wages and employment, which has been synthesized and reviewed extensively. Instead, my intent is to try to identify key questions raised in the recent literature, and some from the earlier literature, which I think hold the most promise for understanding the conflicting evidence and arriving at a more definitive answer about the employment effects of minimum wages.

My secondary goal is to discuss how we can narrow the range of uncertainty about the likely effects of the large minimum wage increases becoming more prevalent in the United States. I discuss some insights from both theory and past evidence that may be informative about the effects of high minimum wages. Although one might argue that we first need to do more to settle the question of the effects of past, smaller increases on which we have more evidence (hence my first goal), I also try to emphasize what research can be done now and in the near future to provide useful evidence to policymakers on the results of the coming high minimum wage experiment.

My review and discussion focus on the U.S. context and evidence. The U.S. experience dominates the literature because of three-plus decades of significant cross-state variation in minimum wages; and the very large minimum wage increases we are likely to see even more of in the United States will likely spur even more work on U.S. minimum wages. But the roadmap to future research on minimum wages should go through other countries as well, for three reasons. First, such evidence will

\footnotetext{
${ }^{5}$ For example, Holtz-Eakin and Gitis (2015) estimated, based on 2014 data, that 55.1 million workers would have been directly affected by raising the federal minimum wage to \$15 by 2020 .
} 
allow researchers to test, in a different context, explanations and hypotheses that arise in studying minimum wages in the United States. Second, policymakers in other countries need evidence on the effects of the minimum wages they adopt. Third, and most important, research in other countries can provide evidence that the U.S. setting cannot provide, such as effects of different institutions for setting minimum wages (like the U.K. Low-Pay Commission, or collective bargaining in other countries), and the effects of implementing a minimum wage where there previously was not one - as in Germany, where the newly founded Minimum Wage Commission will monitor the effects and give policy recommendations in the future.

\section{A Brief Research Overview}

\section{II.1. A Broad Summary}

Regardless of one's precise view of what the U.S. minimum wage literature says about the employment effects of minimum wages, and which studies one finds most convincing, it is clear that there is considerable variation in the magnitude of estimated employment effects across studies.

The evidence for United States has been summarized and reviewed extensively over the past few decades. See Brown et al. (1982), Card and Krueger (1995), and Neumark and Wascher $(2007,2008)$ for earlier reviews, and Belman and Wolfson $(2014,2016)$ for the most recent comprehensive reviews. ${ }^{6}$ Based on this research, the debate regarding the U.S. evidence is often characterized as being about whether the elasticity for low-skilled groups is equal to (or more precisely indistinguishable from) zero, or more likely in the range of -0.1 to -0.2 . But there are also larger negative estimates in the literature (e.g., Clemens and Wither, 2016, and see Table 1 below), and occasional large positive estimates (most notably, Card and Krueger, 1994). ${ }^{7}$

Although my focus in this paper is on U.S. evidence, it is interesting to compare the above survey with evidence for European countries, although I leave it for future work to synthesize the European

\footnotetext{
${ }^{6}$ There are also a few recent meta-analyses of the employment effects of minimum wages. See Neumark (2016) for references to some of these, as well as criticism of their methods.

${ }^{7}$ While this study is frequently cited as showing no evidence of employment effects from minimum wages (e.g., Schmitt, 2015), their results indicate that the increase in New Jersey's minimum wage led to faster employment growth, with an elasticity of 0.73 .
} 
literature to try to identify the key reasons for differences across studies. There is no systematic survey of the large and growing body of European evidence, but some observations can be made. First, it seems fair to say that the debate about minimum wage effects in these countries - as reflected in the literature is similar to that in the United States, with a number of studies finding either no employment effects or disemployment effects in the range of U.S. studies, but also some outliers. We also might expect more variation in the international evidence, given that labor market institutions vary across countries, and the lack of subnational minimums in most countries implies that different identification strategies are used. A brief discussion of some studies (with no claim of being comprehensive) illustrates these points.

The Canadian setting is most like the United States in that minimum wages vary across provinces and over time. In a paper using a pre-specified research design (following Neumark, 2001), Campolieti et al. (2006) focused on 16-24 year-olds (and subsets thereof), and estimated elasticities that ranged from about -0.14 to -0.44 and were centered on about -0.3 . Focused more on low-wage youths, Campolieti et al. (2005) find large negative effects from the minimum wage, with implied overall employment elasticities for youths between -0.33 and -0.54 .

The largest body of non-U.S. evidence is for the United Kingdom, and the U.K. evidence is mixed. Early work on minimum wages set by Wages Councils in the United Kingdom found positive employment effects of minimum wages (Machin and Manning, 1994; Dickens et al., 1999), although this was an institutional setting in which minimum wage setting could have been strongly endogenous. Based on evidence from the abolition of the Wages Council, Dolado et al. (1996) suggested there was no evidence of employment effects, although Neumark and Wascher (2008) suggested their employment data were more consistent with employment growing where Wages Councils were abolished.

More recent evidence - and evidence more relevant to thinking about the introduction of a minimum wage in Germany - comes from the introduction of a national minimum wage in the United Kingdom in April 1999. Machin et al. (2003) surveyed low-wage residential care homes (nursing homes) just before and just after the minimum wage was implemented, and estimated employment elasticities of ranging from -0.08 to -0.39 , most of which were statistically significant. Galindo-Rueda and Pereira 
(2004) also study the introduction of the new minimum wage. One analysis provides some evidence pointing to significant disemployment effects for services but not for manufacturing, and a different analysis identifying minimum wage effects from variation in wage levels across regions finds negative and significant effects in four of the eight low-wage sectors they study, and negative and insignificant effects in three others. ${ }^{8}$

Finally, updating the overall evidence from the United Kingdom, a recent meta-analysis by Leonard et al. (2014) concludes that there is no overall "practically significant adverse employment effect," but that there is variation in estimates, and adverse employment effects in the residential home care industry.

A few recent papers for other European countries illustrate a range of findings. Caliendo et al. (2018) find that the new German minimum wage led to moderate effects on overall employment, driven by a sharp decline in marginal employment - broadly consistent with the U.S. literature finding effects concentrated among those most affected by a higher minimum wage. ${ }^{9}$ Exploiting age discontinuities in the minimum wage in the Netherlands, Kabátek finds sharp increases in separation rates near young ages when the minimum wages increase sharply.

Finally, a couple of papers use minimum wage variation across OECD countries to estimate minimum wage effects. Neumark and Wascher (2004) found little clear evidence of youth disemployment effects in countries with restrictive labor standards and generous employment protections, but elasticities in the -0.2 to -0.4 range in countries with the least regulated labor markets. However, a later paper by Sturn (2018) disputes these conclusions and suggests that the findings of negative effects are fragile.

\section{II.2. Key Issues in Recent Research}

Returning to the U.S. evidence, in the most recent research two key econometric issues underlie

\footnotetext{
${ }^{8}$ Based on other information on entry and exit, the authors interpreted the combined evidence as suggesting that the introduction of the minimum wage had relatively little effect on already employed workers, but exerted more impact through its effect on job creation in low-wage sectors.

${ }^{9}$ Papers in this issue present additional evidence for Germany.
} 
the different answers researchers obtain about whether higher minimum wages reduce employment of low-skilled workers. One concerns the proper specification of control areas (or counterfactuals), given the potential endogeneity or non-randomness of minimum wage increases. Most methods of addressing this problem continue to find negative employment effects. But methods using geographically-close controls tend not to - which leaves us with an open question as to why. The second concerns the inclusion of trends for treated and control areas, and the sensitivity of estimates to those trends. This sensitivity can leave us with little guidance as to which estimates should be preferred.

I focus a good deal of attention on these two issues, to try to indicate how we might progress in making sense of the conflicting estimates in this recent literature. But independently of these two issues emphasized in recent research, there is long-standing evidence of differences in estimated employment effects of minimum wages across studies. In my view, more serious considerations of the economic factors that may help explain these differences could be very fruitful in resolving some of the contradictions in past research. Moreover, since this question has more to do with economics than econometrics, consideration of the factors underlying differences in minimum wage effects across studies may prove useful in thinking about the effects of much higher minimum wages.

\section{Treatment and Control Areas and Identification Strategies}

Estimating causal effects of policy based on past responses to policy changes requires choosing appropriate controls to provide a counterfactual for what would have happened absent the minimum wage increase. In recent decades, the traditional "workhorse” in the empirical literature on the employment effects of state minimum wages in the United States has been the standard two-way fixed effects model with state and time dummy variables - a continuous difference-in-differences (DD) estimator that compares changes in low-skilled employment in states where the minimum wage increased more to states where it increased less (or not at all). Evidence from this estimator (consistent with the earlier time-series literature) is the source of the oft-cited conclusion that the elasticity of employment of low-skilled groups (especially teens) with respect to the minimum wage is in the -0.1 to -0.2 range - a range of estimates that is replicated across many studies, including those discussed below that first report such estimates 
before criticizing the two-way fixed effects estimator and exploring other methods.

\section{III.1. Close Controls}

In two recent influential papers, Allegretto et al. (2011, ADR) and Dube et al. (2010, DLR) raised the concern that cross-state minimum wage variation could be correlated with shocks that also affect employment of low-skilled workers. They compare estimates using the standard two-way fixed effects model in which all states could potentially serve as controls - which yield “conventional” negative elasticities - to estimates based on using only geographically-close areas in different states as controls which yield estimates closer to and statistically indistinguishable from zero. ${ }^{10}$

The idea motivating the use of "close controls" is that the states (or subareas of states) affected by minimum wage increases may experience the same economic shocks to low-skill labor markets as nearby areas unaffected by these increases, and thus comparisons between the treated areas and close controls may more reliably identify the causal effects of minimum wages. The standard two-way fixed effects estimator is

$$
E_{s t}=\beta M W_{s t}+X_{s t} \gamma+D_{s} \theta+D_{t} \lambda+\varepsilon_{s t}
$$

Typically, E is the log of the employment rate or level for a low-skill group like teenagers. MW is the log of the state minimum wage. ${ }^{11} \mathrm{X}$ is a vector of controls. ${ }^{12}$ And the $\mathrm{D}$ vectors are state and year dummy variables (fixed effects). I assume that the data are collapsed to the state by year level (indexed by s and t), but one could use micro-data as well. ${ }^{13}$

\footnotetext{
${ }^{10}$ Card and Krueger (1994) is a precursor of this approach. Other studies that use close controls in a similar fashion to ADR find, not surprisingly, similar results (Addison et al., 2013; Gittings and Schmutte, 2016; and Slichter, 2016). (Addison et al. do find stronger evidence of disemployment effects for teens during the Great Recession.) An exception is Liu et al. (2016), who restrict their close controls to counties in the same BEA "Economic Areas" (but in different states); BEAs are supposed to delineate regionally-integrated markets. Liu et al. find evidence of disemployment effects for the youngest group covered in their data (14-18 year-olds) using the standard two-way fixed effects model, but these are diminished only slightly - to an elasticity of - 0.17 - within Economic Areas. One question is whether the Liu et al. approach actually does a better job of controlling for local economic shocks.

${ }^{11}$ Some research divides the nominal minimum wage by an average wage measure.

${ }^{12}$ As Neumark and Wascher (1994) suggest, given the reduced-form specification, these controls should include exogenous shifters of both labor supply and labor demand.

${ }^{13}$ While almost every paper in the literature studies employment outcomes directly, Cengiz et al. (2017) instead estimate effects on the shares of workers with wages just below or just at or above the minimum wage. The authors suggest that this approach can avoid biases from changes in employment unrelated to the minimum wage, and generally do not find evidence of job loss. One curious finding, though - a very large positive implied employment
} 
The concern raised by ADR and DLR is that $\varepsilon$ is correlated with MW in equation (1). In the context of a state-level analysis (as in ADR), for example, let $r$ index regions that includes subsets of states. Then as long as the shocks are common to regions, one can control for them by augmenting the model with interactions between year and region dummy variables, as in

$$
E_{s t}=\beta M W_{s t}+X_{s t} \gamma+D_{s} \theta+D_{t} \lambda+D_{t} \cdot D_{r}^{T} \eta+\varepsilon_{s t .}{ }^{14}
$$

As long as there is within-region variation in the minimum wage, $\beta$ is identified - from these regions. The approach in DLR is the same, except that they use county-level data, where r indexes sets of bordering counties across state lines, and identification comes from the county "pairs" where the minimum wage variation differs on the two sides of the border. DLR use employer data, and hence focus on low-wage industries (like restaurant workers) rather than teenagers.

The implication from the evidence in both papers that estimated minimum wage effects are less negative (and insignificant) when using close controls implies that minimum wages tend to be increased where there are negative shocks to employment in low-skill labor markets. Later, I discuss whether this is likely and what other evidence implies. The results of these and other recent studies discussed below are summarized in Table 1.

\section{III.2. Responses to Concerns about Non-Random Minimum Wage Variation}

There have been three kinds of responses to the legitimate concern about the non-random nature of minimum wage variation (conditional on state and year fixed effects). First, research has explored the validity of the controls ADR and DLR used (Neumark et al., 2014a; Neumark and Wascher, 2017). ${ }^{15}$ Second, researchers have pushed further the development of synthetic control methods (Abadie et al., 2010) to select or construct appropriate control areas (most notably, Powell, 2016). And third, several studies have adopted alternative identification strategies to isolate the effects of minimum wage increases from shocks that are potentially correlated with them.

elasticity for high school dropouts - suggests that the method may not be immune from spurious effects. I leave it to future work to consider this approach more fully.

${ }^{14}$ Depending on how many region-by-year interactions are omitted, these interactions could subsume the year fixed effects.

${ }^{15}$ See the response to this research in Allegretto et al. (2017). 
In the latter category, the approach used most widely in reduced-form analyses of policy effects, generally, is triple-differences (DDD) estimators that isolate the effect of the policy change by introducing another group in the same state that is "exposed" to the same policy change but is less affected by it (or not at all affected), and is assumed to experience the same shock - which is the identifying assumption. Thompson (2009), which predates ADR and DLR, helps motivate this approach, although he does not use a full DDD approach. Thompson focuses only on variation generated by the two federal minimum wage increases in 1996 and 1997, restricted to the states where the federal minimum wage was binding. He generates minimum wage variation by differentiating counties by the extent to which the minimum wage is binding. Indexing counties by c, defining $\mathrm{H}$ to be an indicator that minimum wages are more binding in a county, and defining POST as an indicator for the period after the federal minimum wage increases, he estimates models of the form

$$
\mathrm{E}_{\mathrm{cst}}=\beta \mathrm{POST}_{\mathrm{t}} \cdot \mathrm{H}_{\mathrm{cs}}+\mathrm{X}_{\mathrm{cst}} \gamma+\mathrm{H}_{\mathrm{cs}} \psi+\mathrm{D}_{\mathrm{s}} \theta+\operatorname{POST}_{\mathrm{t}} \lambda+\varepsilon_{\mathrm{cst}} .
$$

Equation (3) is a difference-in-differences (DD) estimator, identifying $\beta$ from the differential change in employment in counties where the minimum wage increase affected more workers $(\mathrm{H}=1)$ versus fewer workers (with a focus on young people and teenagers). This estimator should avoid endogenous minimum wage changes at the state level by comparing regions within a state, and by using only federal variation. Thompson finds large disemployment effects in counties where minimum wages are more binding because wages are lower, and workers are lower skilled. (The second panel of Table 1 covers strategies different from the “close-controls” approach, including Thompson’s.)

One could use this approach in a DDD framework by using a period with state variation in minimum wages, and identifying the effects from differential impacts across more- and less-affected subareas of states, allowing for a full set of state-by-year interactions, as in

$$
E_{c s t}=\beta M W_{s t} \cdot H_{c s}+X_{c s t} \gamma+H_{c s} \psi+D_{s} \theta+D_{t} \lambda+D_{t} \cdot D_{s}^{T} \eta+\varepsilon_{c s t}{ }^{16}
$$

Clemens and Wither (2016) follows this strategy of including state-by-period fixed effects to

\footnotetext{
${ }^{16}$ In this specification, the main effect of the minimum wage is subsumed in the state-by-year interactions. The full DDD specification would include other interactions I have omitted, such as $\mathrm{D}_{\mathrm{t}} \cdot \mathrm{H}_{\mathrm{cs}}$. This is the approach taken, in a slightly different context (the effects of minimum wages on automatable jobs) in Lordan and Neumark (2018).
} 
control for state-specific shocks. They estimate the effects of the 2007-2009 federal minimum wage increases, comparing changes in employment for the lowest-wage workers whose wages were differentially affected by the federal increases (because of prior variation in state minimum wages), to changes in employment for workers who earned wages that were low, but high enough that the federal minimum wage increases had little impact on them. ${ }^{17}$ Thus, $\mathrm{H}_{\mathrm{cs}}$ in equation (4) becomes an indicator for the lowest-wage workers. They estimate a large employment elasticity for directly affected workers (about -0.97 based on Survey of Income and Program Participation (SIPP) data). ${ }^{18}$

As an alternative strategy for addressing shocks potentially correlated with state minimum wage increases, Baskaya and Rubinstein (2015) use an instrumental variables (IV) approach (in estimating the effects of minimum wages on teen employment). Their IV is the interaction between the federal minimum wage and a measure of the historical propensity for each state to let the federal minimum wage bind, which is intended to purge the estimated minimum wage effect of bias from states endogenously choosing their minimum wage in response to shocks to state-level economic conditions. I view this IV as particularly clever; when I thought about IV strategies in the past, most candidate IVs (such as the political orientation of a state) would be fully absorbed by state and year fixed effects.

Their first-stage equation is

$\mathrm{MW}_{\mathrm{st}}=\varphi \mathrm{F}_{\mathrm{s}} \mathrm{MW}_{\mathrm{t}}^{\mathrm{F}}+\mathrm{X}_{\mathrm{st}} \gamma+\mathrm{D}_{\mathrm{s}} \theta+\mathrm{D}_{\mathrm{t}} \lambda+\varepsilon_{\mathrm{st}}$

$\mathrm{MW}_{\mathrm{t}}$ is the federal minimum wage, and $\mathrm{F}_{\mathrm{s}}$ is the fitted value from a model for the probability that legislators allow the federal minimum to bind in the state

$$
F_{s}=P\left(Z_{s} \pi\right)
$$

$\mathrm{Z}$ includes measures of cross-state differences in standards of living and political preferences, as well as the proportion of years earlier in the sample when the federal minimum wage was binding. ${ }^{19}$

\footnotetext{
${ }^{17}$ Similar to Thompson (2009), the use of contemporaneous variation generated by federal policy likely also reduces problems of endogenous minimum wage variation.

${ }^{18}$ Foreshadowing the discussion below, the magnitude is likely larger than other studies because it is calculated for a more directly-targeted group of workers (compared to teenagers or restaurant workers, only some of whom are paid at or near the minimum wage). Indeed, Clemens and Wither show that the elasticity is smaller when using a treatment group that includes higher-wage workers and hence is "less intensively" treated.

${ }^{19}$ In these earlier years, many states had minimum wages lower than the federal level applied to workers not covered by the FLSA, who were quite numerous before expansions of coverage of the FLSA in 1977 (Brown et al., 1982).
} 
Their IV elasticity estimates for teenagers are in the range -0.3 to -0.5 . These estimates exceed the OLS (standard two-way fixed effects) estimates, which is consistent with policymakers raising minimum wages when youth labor market conditions are strong, and contrasts with the direction of bias implied by the close-controls estimates in ADR and DLR.

The approaches considered thus far rely, in large part, on a priori specification of alternative controls or a priori assumptions about how to construct a valid counterfactual. For example, ADR and DLR assert that geographically-close controls are better than the larger set of control states used in the standard two-way fixed effects estimator. Baskaya and Rubinstein (2015) rely on an a priori assumption regarding the validity of their instrumental variable. And Clemens and Wither (2016) rely on the assumption that slightly higher-wage workers provide valid controls. ${ }^{20}$

In contrast, synthetic control methods (Abadie et al., 2010) rely on a more data-driven approach to construct controls. The synthetic control model can be motivated by a factor model that is less restrictive than the standard two-way fixed effects model

$$
E_{s t}=\beta M W_{s t}+X_{s t} \gamma+\tau_{t} \theta_{s}^{T}+\varepsilon_{s t}
$$

$\tau_{\mathrm{t}}$ is a row vector of period factors and $\theta_{\mathrm{s}}^{\mathrm{T}}$ is a column vector of region factors. If, for example, $\tau_{\mathrm{t}}$ $=\left(\begin{array}{ll}1^{\mathrm{s}} & \varphi_{\mathrm{t}}\end{array}\right)-\mathrm{a}$ row vector of 1 's for each state s and time fixed effects - and $\theta_{\mathrm{s}}=\left(\omega_{\mathrm{s}} 1^{\mathrm{t}}\right)-\mathrm{a}$ row vector of state fixed effects and 1's for each year t (transposed in the equation) - then we get the standard two-way fixed effects model. However, with greater flexibility the state fixed effects need not be constant across time (for example), in which case taking differences across time does not eliminate the state fixed effects. Still, equation (7) entails some restrictions; for example, the state factors can only be multiplied by common factor in a given year.

The synthetic control approach can provide an unbiased estimate in this more general setting (as

\footnotetext{
${ }^{20}$ The papers tend to present indirect evidence in support of their approaches. For example, ADR and DLR suggest that estimators that do not use their close controls are more contaminated by "pre-trends" that could reflect endogeneity of minimum wage increases with respect to shocks to low-skill labor markets (although Neumark et al. (2014a) and Neumark and Wascher (2017) raise questions about this evidence). And Clemens and Wither present evidence based on wage effects that are consistent with their assumption, although they cannot directly test their assumption with respect to employment.
} 
well as even more general settings), using a weighted set of control regions that matches pre-treatment data in the treated regions to provide an estimate of how the outcome would have evolved in the treated regions absent the treatment. For example, the synthetic control model allows time-varying state effects consistent with the more flexible factor model in equation (7) - but assumes that how they vary in the post-treatment period is similar in the treated region and the synthetic control regions.

The original application of synthetic control methods in Abadie et al. (2010) was to a single, categorical treatment in one region (a tobacco control program in California), with many possible control states. ${ }^{21}$ However, the application to minimum wages is typically more problematic, because there are potentially scores of minimum wage increases, these increases vary in magnitude, and potential pretreatment controls may be contaminated by prior minimum wage increases (including possibly lagged effects). ${ }^{22}$ In this setting, synthetic control methods have been used in a few ways.

Neumark et al. (2014a) did not focus directly on estimating minimum wage effects, but instead on a "first-stage" synthetic control analysis asking whether the synthetic control method would pick out the close controls that ADR and DLR advocated using. For example, ADR use state data and define their close controls as states in the same Census divisions (and hence include Census division-by-year interactions in equation (2)). If there are common shocks within Census divisions, but not across Census divisions, then the synthetic control method should put most of the weight on same-division states that would better match the prior variation in the treatment states. In contrast, if the analysis puts relatively less weight on same-division states, this would imply that those states are not the best controls, and that restricting the identifying information only to within-division variation in minimum wages may be less likely to identify the true effect of minimum wages.

As an illustration, Table 2 reports results from matching on three different forms of the dependent variable, each defined over the four pre-treatment quarters. This matching is done for states without

\footnotetext{
${ }^{21}$ Another example is Bohn et al.’s (2014) analysis of Arizona’s 2007 anti-immigration law.

${ }^{22}$ Researcher have used synthetic control methods to estimate the effects of a single minimum wage increase. Jardim et al. (2017) and Reich et al. (2017) estimate the effects of Seattle's \$2 minimum wage increase in 2016 (to \$13, on the way to \$15). And Sabia et al. (2012) and Hoffman (2016) study the impact of New York’s 2005 minimum wage increase.
} 
minimum wage increases in that period. This allows 129 unique treatments in the sample period used, for which 50 have potential control donors in the same Census division, covering six divisions. The weights from the matching process on states in the same division are reported in columns (1)-(3). Except for the West North Central division, these weights are generally well below one. In 13 out of the 18 cases they are below 0.30 , and in some cases, they are quite close to zero, implying that most of the weight chosen by the synthetic control method is on states outside the division. ${ }^{23}$

Calculations based on this analysis demonstrate that there is generally little reason to prefer the same-division states as controls relatively to randomly-chosen states. For the analysis in columns (1)-(3), the average weight per same-division donor state is higher than the random threshold of $1 /$ (number of potential donors) in only 24, 17, and 19 cases (out 50 cases in column (1), and 49 and 44 and cases in columns (2) and (3), owing to some loss of observations from the lagged variables). That is, for most Census divisions, states outside the Census division tend to be better control observations, militating against the ADR and DLR criticism of the two-way fixed effects model.

Other analyses have tackled the challenge of trying to use synthetic control methods to estimate employment effects using a broad set of U.S. minimum wage increases. Neumark et al. (2014a, 2014b), in a manner explicitly acknowledged as ad hoc, estimated the effects of a large set of minimum wage increases by first using the two-way fixed effects model to estimate minimum wage effects, and then matching on the estimated regression residuals; to try to bound the estimates, they used the same procedure assuming that the minimum wage effects were zero. This analysis led to evidence of disemployment effects in both the state and county context. Dube and Zipperer (2015) used a different method of using multiple (but far fewer) minimum wage increases in a synthetic control framework. They restrict attention to potential controls with no minimum wage increases in the prior two years,

\footnotetext{
${ }^{23}$ Columns (4)-(6) report the average number of divisions and states in the donor pool, and the average number of states in the same division, and show that the low weight on states in the same division is not attributable to a small number of potential donor states from the same division. For example, Pacific has a low number of potential donors from the same division relative to all potential donors, but relatively high weight, and South Atlantic has a high number of potential donors from the same division relative to all potential donors, but relatively low weight.
} 
allowing them to study 29 minimum wage increases out of 215 in their sample period. ${ }^{24}$ They find smaller and statistically insignificant negative employment effects.

Most recently, in what appears to be the most satisfactory and flexible approach, Powell (2016) develops and uses a method that can be applied to multiple treatments with continuous variation, and that simultaneously estimates the treatment effect and the weights on the control states. His method avoids the problem of selecting minimum wage increases with clean controls, and hence can use all the data. Powell finds a statistically significant estimated elasticity for teens of -0.44 .

Totty (2017) uses a linear factor model that also does not impose close controls but is more restrictive than Powell’s synthetic control approach. He finds small (and insignificant) negative employment effects for restaurant workers and teens. However, although the idea behind this approach (see, e.g., the common correlated effects, or CCE, estimator of Pesaran, 2006) is to avoid specifying the form of the unobserved heterogeneity (see, e.g., Totty, p. 1716), Totty always includes state and year fixed effects and uses the CCE (and another estimator) to allow for other forms of heterogeneity. The standard two-way fixed effects estimator yields elasticities of -0.14 for restaurant employment and -0.18 for teen employment, while his alternative estimators yield smaller and insignificant elasticities. Totty argues for including the two-way fixed effects a priori to address the specific debate in the minimum wage literature - discussed later - about including jurisdiction specific trends along with the traditional two-way fixed effects. He states that "the factor model results are essentially unchanged if the two-way fixed effects are removed from the specification” (footnote 15). Based on estimates he provided to me, this is true for the results for teens, but not for restaurant workers, for whom the less restrictive approach yields elasticities of -0.048 to -0.066 (significant at the 5-percent or 10-percent level), in contrast to the insignificant estimates of about -0.01 to -0.02 reported in Table 3 of his paper.

In related work, Colangelo and Harding (in progress) explore the two-way fixed effects model using data from ADR. For 16-17 year-olds (they never find an employment effect for 18-19 year-olds),

\footnotetext{
${ }^{24}$ An important feature of this approach is correct (indeed, exact) statistical inference, whereas Neumark et al. (2014a) acknowledged an inability to compute correct standard errors for their two-step approach.
} 
they show that using CCE after first assuming fixed state and year effects gives an employment effect that is smaller than the two-way fixed effects estimate (the latter is significant, the former is not), whereas using CCE without first imposing this structure on the unobservables yields a negative and significant employment effect that is very close to the two-way fixed effects estimate; the implication is that the twoway fixed effects estimate is not biased. However, the negative hours effect obtained from the two-way fixed effects specification is not robust to using the CCE estimator. Thus, there appears to be some remaining uncertainty about the implications for minimum wage effects of estimating models with weaker a priori restrictions imposed on the structure of the unobservables.

The factor model originally appeared to have some advantages, given the difficulties of applying the synthetic control approach to an unrestricted analysis of minimum wages. However, the Powell study appears to surmount these difficulties, and hence is probably more compelling.

The results discussed above, and some others from the recent literature, are summarized in Table 1. In my view, this table establishes the rather clear result I alluded to earlier: Studies using close controls generally find small disemployment effects that are indistinguishable from zero. But other identification strategies - differencing estimators that control for state-specific shocks, IV estimates that purge the minimum wage variable of correlation with these shocks, as well as the most advanced synthetic control estimator (Powell, 2016) - tend to find larger disemployment effects.

III.3. Should We Be Convinced by the Absence of Disemployment Effects from Close-Control Strategies?

This evidence poses two questions: Why do the different strategies generate different results? And which strategy or strategies is most reliable? I do not have a complete answer, but I discuss two additional lines of inquiry that have been suggested in the literature - aside from the question considered in Neumark et al. (2014a) of whether close controls are better controls. ${ }^{25}$ These lines of inquiry have focused on the validity of the close-controls approach, although of course the validity of all of the methods merits attention.

\footnotetext{
${ }^{25}$ For further exchanges on these findings, see Neumark et al. (2014b), Allegretto et al. (2017), and Neumark and Wascher (2017).
} 
One issue, raised by Neumark et al. (2014b), is that minimum wage increases within similar geographic areas could be more endogenous with respect to economic shocks, rather than less. Other factors that differ more substantially between states in different regions, and that provide exogenous variation - such as unionization or politics - likely play less of a role for close controls, implying that differences in economic conditions between treatment states and close controls, even if smaller, may matter more for determining minimum wages. As Jeffrey Clemens once remarked, "If the regions are so damn similar, why do they have different minimum wages?”

A useful analogy comes from Griliches’ (1979) seminal work on twin or sibling estimates of the economic returns to schooling. The simple intuition is that if we include family fixed effects, or equivalently look only at within-family variation in schooling and wages, then bias from omitted unobservables at the family level is reduced. Griliches noted, however, that whether bias in the estimated return to schooling is reduced in the within-family differences depends on what generates variation within versus across families. For example, if family influences or "background” common to both siblings or twins are relatively important in determining schooling, then the remaining within-family differences can be more reflective of ability differences to which schooling responds, in which case the within-family estimate of the return to schooling can be more biased than an estimate using across-family variation.

For the simplest analogy to estimating minimum wage effects, suppose we have only two years of data, form the first differences between treated states (s) and bordering states (s'), and estimate

$$
\left(\Delta \mathrm{E}_{\mathrm{s}}-\Delta \mathrm{E}_{\mathrm{s}^{\prime}}\right)=\beta \Delta \mathrm{MW}_{\mathrm{s}}+\left(\Delta \mathrm{X}_{\mathrm{s}}-\Delta \mathrm{X}_{\mathrm{s}^{\prime}}\right) \cdot \gamma+\left(\Delta \varepsilon_{\mathrm{s}}-\Delta \varepsilon_{\mathrm{s}^{\prime}}\right){ }^{26}
$$

Suppose there is a shock correlated with $\Delta \mathrm{MW}_{\mathrm{s}}$ - denote it $\Delta \mu_{\mathrm{s}}$. If we assume the shock in the first difference for state s' $\left(\Delta \mu_{s^{\prime}}\right)$ is the same, then it drops out of equation (8) and we obtain an unbiased estimate of $\beta$. In contrast, if we use control states further away, the shocks are less likely to be the same, and estimators that do not rely solely on close controls will be biased. This is the rationale for closecontrols estimators.

But like the assumption that identical twins (the strongest case) have identical unobservables, the

${ }^{26} \Delta \mathrm{MW}_{\mathrm{s}}{ }^{2}=0$, since s' denotes the untreated states. 
assumption that the shock is identical in the treatment and close-control states is likely not strictly true. That is, there is an omitted variable in equation (8) equal to $\left(\Delta \mu_{\mathrm{s}}-\Delta \mu_{\mathrm{s}^{\prime}}\right)$. The simple intuition that might still rationalize the close-controls estimator is that the difference in shocks must be a good deal smaller than between a treatment state and some other (not close) state or set of states. However, this does not imply less bias. The omitted variable bias in equation (8), ignoring the $\mathrm{X}$ terms, is

$$
\operatorname{Cov}\left(\Delta \mu_{\mathrm{s}}-\Delta \mu_{\mathrm{s}}, \Delta \mathrm{MW}_{\mathrm{s}}\right) / \operatorname{Var}\left(\Delta \mathrm{MW}_{\mathrm{s}}\right){ }^{27}
$$

The only assertion about the shocks in different sets of states that is compelling a priori is that $\operatorname{Var}\left(\Delta \mu_{\mathrm{s}}-\Delta \mu_{\mathrm{s}^{\prime}}\right)$ is smaller for nearby states than farther way states. But equation (9) shows that two different magnitudes form the bias in the close-controls estimator.

First, is $\operatorname{Cov}\left(\Delta \mu_{\mathrm{s}}-\Delta \mu_{\mathrm{s}^{\prime}}, \Delta \mathrm{MW}_{\mathrm{s}}\right)$ necessarily lower for close states? This takes us back to the question of what drives minimum wage variation between nearby states. Here is one possibility in which the covariance would be higher for nearby states. Suppose policymakers respond to changes in low-skill labor markets in setting minimum wages, but they also respond to other factors. In two distant states, because they differ on many dimensions, the other factors (or, more precisely, changes in those factors), vary more. In contrast, in bordering states, because of their assumed homogeneity, the other factors do not differ. In that case, even though $\operatorname{Var}\left(\Delta \mu_{\mathrm{s}}-\Delta \mu_{\mathrm{s}^{\prime}}\right)$ is higher for the farther state pairs, $\operatorname{Cov}\left(\Delta \mu_{\mathrm{s}}-\right.$ $\Delta \mu_{\mathrm{s}}, \Delta \mathrm{MW}_{\mathrm{s}}$ ) is higher for the bordering states.

Second, the denominator in equation (9), $\operatorname{Var}\left(\Delta \mathrm{MW}_{\mathrm{s}}\right)$, is generally lower for nearby states, because of a strong regional component to minimum wages; for example, New England states are more likely to border other New England states that tend to have higher minimum wages. This, in itself, will exacerbate the bias in the close-controls estimator.

This discussion about potential bias in the close-controls estimator is speculative. (At the same time, the claim that the close-controls approach is necessary to get unbiased estimates of minimum wage effects is also speculative.) But since I am already speculating, let me take it a bit further.

My hypothesis about influences of labor market conditions on minimum wages is that some

\footnotetext{
${ }^{27}$ Formally, this is the inconsistency, derived from taking probability limits.
} 
policymakers like to increase the minimum wage, maybe because they think it is a good idea, but also because minimum wages are popular. ${ }^{28}$ But policymakers also know that they get blamed for poor economic developments that coincide with the policies they choose, regardless of whether the policies are to blame. Thus, policymakers will tend to raise minimum wages when there are positive shocks to lowskilled labor markets. ${ }^{29}$ The average positive pre-trend prior to minimum wage increases that Monras (2015) estimates is consistent with this story, as is the stronger disemployment effect that Baskaya and Rubinstein (2015) estimate using their IV.

More importantly, if we couple this with the argument above - that minimum wage variation between nearby states is more correlated with shocks to low-skilled labor markets than is minimum wage variation between non-close states, then this contributes to greater positive bias in the estimates of $\beta$ from the close-controls approach. The alternative, of course, is that the close-control estimates are the unbiased ones, in which case we would have to believe that policymakers tend to raise minimum wages when lowskilled labor markets are deteriorating, which I find less plausible, and which is less consistent with other evidence.

What we need, clearly, is research that gets beyond this speculation. This research needs to better illuminate the determination of minimum wage variation, as well as how the determination of this variation influences the different estimators. Of course, if we have a means of implementing a synthetic control estimator across all minimum wage increases, as in Powell (2016), then maybe this point is now moot with respect to the U.S. evidence, because we do not need to rely on a priori assumptions about which controls are valid. Still, it would be better to uncover - if we can - an empirically-grounded, behavioral basis for specifying control areas. More generally, researchers seem to accept cross-border research designs as valid, rather uncritically. ${ }^{30}$ It seems useful, then, to think about economic analyses of

\footnotetext{
${ }^{28}$ See, e.g., https://www.thirdway.org/memo/americans-want-to-raise-the-minimum-wage-but-not-the-way-dcthinks (viewed June 30, 2018).

${ }^{29}$ It has to be a little more complicated than this because the error term of interest in this discussion is typically from a model for low-skill labor market outcomes conditional on an aggregate cyclical measure. Also, the last federal increases in the United States coincided with the Great Recession, hardly a time of improving labor markets. However, my hypothesis is intended to help explain the local variation at issue in most of the recent literature.

${ }^{30}$ For two recent examples in other contexts, see de Blasio and Poy (2017) and McVicar et al. (2018). There are a number of other examples in the tax literature.
} 
cross-border policy variation that might tell us when such designs are more likely to be useful.

This is a good segue into another issue related to using close controls - the potential role of spillovers between treated and control areas. A recent theoretical contribution by Zhang (2017) models such spillovers in a search model of minimum wages and demonstrates why such spillovers could generate bias against finding disemployment effects in close-control research designs. In his model, there are two areas between which workers can commute or migrate, one of which raises its minimum wage. Workers are heterogeneous (high and low skilled). Workers initially are randomly distributed across the two areas, but firms decide where to post jobs. Search is random, so workers in both locations are contacted by firms at the same rates. The bargained wage depends in part on the worker's quality and is truncated by the minimum wage. Workers also make commuting or migration decision based on the trade-off between the wage offers they receive and the moving cost they need to pay.

A higher minimum wage on one side of the border attracts neighboring high skilled workers to move or commute in, due to higher wages. Local firms therefore create more job vacancies, because the greater proportion of high-quality workers makes those vacancies more likely to be filled with highquality workers and thus become more productive. At the same time, there is some gross disemployment falling on low-skilled workers as a higher minimum wage leads marginally productive matches to end. In equilibrium, the higher minimum wage area experiences an influx of high-quality workers and an outflow of low-quality workers, and the latter generates negative externalities for low-quality workers in the area where the minimum wage did not increase.

Cross-border designs can therefore understate disemployment effects for two reasons. First, unemployed workers migrate from the treated area, obscuring the lower employment rate in the treatment areas. Second, they move to or commute to the control area, reducing the employment rate and perhaps employment there (the latter from fewer vacancies), contaminating the control group in a way that further obscures job loss in the treatment area relative to the control area.

Zhang presents two types of supporting evidence. First, lower-quality workers (based on 
education) tend to migrate or commute from counties where minimum wages increase. ${ }^{31}$ Second, he presents calculations suggesting that the diminution of the disemployment effect from using neighboring counties as control areas can be due to labor mobility, rather than the spatial heterogeneity that Dube et al. (2010) (and Dube et al., 2016) emphasize. Zhang also presents empirical evidence consistent with this argument, showing that the diminution of the disemployment effect from using cross-border counties as controls is stronger where moving costs are lower (because of distance). ${ }^{32,33}$

Thus, I think there are two possible positions regarding using close-control research designs to estimate minimum wage effects. The favorable position is that these methods uncover unbiased estimates of the disemployment effects of minimum wages, which are near zero. Other methods, including those that try to account for the potential correlation between minimum wage changes and shocks to low-skilled labor markets, generate biased estimates that suggest disemployment effects. This is presumably because policymakers tend to raise local minimum wages in concert with negative shocks to low-skilled labor markets, and the other methods used in recent literature for some reason do not capture this mechanism. The alternative position is that the close-controls approach is biased against finding disemployment effects, perhaps because of mobility and spillover effects, and/or because close-control designs exacerbate positive endogeneity bias in estimated disemployment effects of minimum wages.

In my view, there is more evidence for the latter position. This includes the evidence in Neumark et al. (2014a) suggesting that close controls are not better controls, reinforced by the evidence from Powell (2016) that a comprehensive synthetic controls analysis produces rather strong disemployment effects. It also includes the evidence in Zhang (2017) - predicted by his model - that mobility and spillover effects generate a bias towards zero in close-controls estimates of disemployment effects. Finally, the evidence from recent research using different methods of controlling for endogenous

\footnotetext{
${ }^{31}$ Pérez Pérez (2018) reports similar evidence, finding that when minimum wages increase along a border, lowwage commuting into the affected area declines, and the low-wage employment share declines.

32 The minimum wage and cross-border flows have also been studied by McKinnish (2017) - who reports evidence consistent with Zhang's - Kuehn (2016), and Shirley (forthcoming). More general evidence on minimum wages influencing migration (focusing on location decisions of low-skilled immigrants) is reported in Cadena (2014).

${ }^{33}$ Another potential reason that cross-border designs can understate disemployment effects is policy spillovers to wages across the border (Jardim et al., in progress).
} 
minimum wages (i.e., not close controls) finds stronger disemployment effects of minimum wages (Baskaya and Rubinstein, 2015; and Clemens and Wither, 2016) - consistent with the opposite direction of bias generated by endogenous policy responses from that suggested by close-controls designs.

At the same time, I think we are quite far from a definitive answer. More research assessing the reasons for different estimates of employment effects of minimum wages from different research designs would be very valuable.

\section{Trends}

Another issue highlighted in recent work - related to the construction of the counterfactual but not in as transparent a way - is the inclusion of trends in models estimating the employment effects of minimum wages. This issue arises in using the standard two-way fixed effects model, and in models for employment growth that are motivated by new theoretical models of minimum wage effects.

\section{IV.1. Including Trends in the Standard Panel Data Model}

In reduced-form, panel data analyses of policy effects it is quite standard to include linear time trends specific to the states (or other jurisdictions) under study. This is intended to correct for violations of the "parallel trends” assumption by controlling for cross-state differences in the evolution of outcomes that were present absent the policy change. However, recent work has demonstrated that estimated employment effects of minimum wages can be quite sensitive to the inclusion of state-specific time trends. ${ }^{34}$ For example, in the standard two-way fixed effects model, ADR showed that estimated employment effects were quite sensitive to including state-specific linear trends (going to near zero in this case). However, Neumark et al. (2014a) showed that this conclusion was fragile; when higher-order trends were included, the estimated employment effects reverted to being negative. At a minimum, this illustrates that we should do more than just check the sensitivity of estimates to including linear trends.

The broader point, though, is that the inclusion of trends (especially for outcomes that are not naturally trended, like employment rates) is ultimately a profession of our ignorance, in two dimensions. (I am putting aside the notion that including trends corrects for policy endogeneity. I cannot think of a

\footnotetext{
${ }^{34}$ See Allegretto et al. (2011, 2017), Neumark et al. (2014a), and Neumark and Wascher (2017).
} 
good reason why trends - linear or otherwise - would capture explicit endogeneity. And the kinds of approaches discussed in the previous section are more appropriate for addressing this issue.)

First, the appeal to including trends is typically based on the hypothesized influence of omitted variables that underlie these trends. ${ }^{35}$ This suggests that more compelling evidence will come from expanding the variables used in minimum wage studies to include the hypothesized omitted variables.

And we should have extra motivation to pursue this line of inquiry given that results are non-robust across different ways of including time effects to capture these unmeasured variables. Most employment equation specifications in the minimum wage literature use quite parsimonious controls, often including only an aggregate labor market indicator and a relative supply variable (like the share of the young population in the total population). This is rather striking relative to research on other topics where a much more extensive list of controls is typically included. I think the reason for this parsimony is that research papers try to build incrementally on past work - changing the estimation method, for example, and not wanting to confound the effects of doing this with the effects of varying the control variables relative to earlier literature. But the sensitivity of estimates to the inclusion of trends suggests that a change in strategy might be warranted. Indeed, a couple of recent papers introduce richer sets of controls (Clemens and Wither, 2016; and Clemens and Strain, forthcoming). ${ }^{36}$

The second dimension of our ignorance concerns how to introduce and estimate trends when we still want to include them. One issue is functional form. There is nothing sacred about linear trends. In fact, Neumark et al. (2014a) suggest that linear trends can be particularly problematic when business cycles affect the estimated trends, and in some contexts linear trends can lead to impossible implied values of dependent variables (such as an employment rate below zero or above one). A second issue is how we distinguish between trends and treatment effects - an issue discussed in more detail in the next subsection. We should probably explore estimating trends using only the pre-treatment period and using these estimated trends to detrend the post-treatment data, to avoid confounding policy effects and

\footnotetext{
${ }^{35}$ For example, Allegretto et al. (2011) refer to unmeasured changes in technology leading to teens experiencing increased competition from adults for low-skilled jobs.

${ }^{36}$ In the latter, adding richer controls tends to strengthen adverse employment effects estimated for 16-21 year-olds.
} 
estimation of trends. As an example, Monras (2015) removes the trend fitted to the pre-treatment period for a specific number of periods. ${ }^{37}$

\section{IV.2. Dynamic Models}

In recent work, Meer and West (2016) demonstrate in a dramatic way the problem that trends can absorb treatment effects. They do this in the context of estimating effects of minimum wages on employment growth, although the same holds true for more conventional models focused on levels. ${ }^{38}$ Most prior research has not studied effects of minimum wages on employment growth. However, recent models using a "putty-clay” approach to technology have suggested that minimum wages may have small initial effects on employment but increasing effects over time, as new technology comes on line that uses less low-skilled labor (e.g., Sorkin, 2015).

To see the basic idea in Meer and West in a simple way, suppose that the minimum wage can change both the level and the rate of growth of employment, so that the correct model absent trends is

$$
E_{s t}=\beta \cdot M_{s t}+\beta \cdot \cdot \cdot M W_{s t}+X_{s t} \gamma+D_{s} \theta+D_{t} \lambda+\varepsilon_{s t}
$$

If the growth effect $(\mathrm{t} \cdot \mathrm{MW}$ st) is omitted, and one instead estimates the standard two-way fixed effects model, then part of the effect of $\mathrm{t} \cdot \mathrm{MW}_{\text {st }}$ will load onto the simple effect of $\mathrm{MW}_{\text {st. }}$ To simplify further, suppose there are two states, and there is a single minimum wage that starts to increase in one state beginning in in period t', which is between $t=1$ and $t=T$. Then as long as the panel is somewhat long, some of the growing shortfall in employment (assuming $\beta^{\prime}<0$ ) in the treated state will be captured in the estimate of $\beta$, when $\mathrm{t} \cdot \mathrm{MW}$ st is omitted.

But suppose that, in addition to omitting $\mathrm{t} \cdot \mathrm{MW}_{\mathrm{st}}$, a researcher includes state-specific trends, so the model becomes

$$
E_{s t}=\beta \cdot M_{s t}+X_{s t} \gamma+D_{s} \theta+D_{t} \lambda+D_{s} \cdot t \psi+\varepsilon_{s t}
$$

In this case, the included trends can pick up the effect of the omitted variable $t \cdot \mathrm{MW}_{\mathrm{st}}$, even if

\footnotetext{
${ }^{37}$ Monras also estimates a separate post-treatment trend, which he alternately considers as part of the treatment effect (à la Meer and West, 2016, discussed below) or not part of the treatment effect.

${ }^{38}$ Of course, the effects of minimum wages in a model for employment growth also involves the issue of trends, since now the data are detrended by first-differencing, with the difference that the effect of minimum wages is modeled as an effect on the growth rate of employment (log differences).
} 
there are no true state-specific trends in the model. This is less likely if t' is close to T and far from 1 , because then there is a long pre-treatment period with which to identify the parameter $\psi$ that captures the trend difference between changes in $\mathrm{E}_{\mathrm{st}}$ in the treatment and control states. Put differently, if the minimum wage increases start late in the panel, then the correlation between $t \cdot \mathrm{MW}_{\mathrm{st}}$ and $\mathrm{D}_{\mathrm{s}} \cdot \mathrm{t}$ is relatively weak, and less of the minimum wage effect will load onto the estimate of $\psi$. But if t' is close to 1 , there is only a short pre-treatment period, and more of the effect of $\mathrm{t} \cdot \mathrm{MW}_{\text {st }}$ will load onto the estimate of $\psi$, obscuring the minimum wage effect.

The problem is mitigated, of course, by estimating the correct (or, at least, unrestricted) model

$$
E_{s t}=\beta \cdot M W_{s t}+\beta \cdot t \cdot M W_{s t}+X_{s t} \gamma+D_{s} \theta+D_{t} \lambda+D_{s} \cdot t \psi+\varepsilon_{s t}
$$

The results in Meer and West are consistent with the problem highlighted by equations (11) and (12). Their standard two-way fixed effects estimate of the employment elasticity is -0.15 , significant at the $1 \%$ level. But adding state time trends reduces this elasticity to a small and insignificant -0.013 (their Table 2). Of course, this evidence is equally consistent with equation (11) being the correct model, and the negative minimum wage effect being a spurious reflection of state-specific time trends.

However, Meer and West present three types of evidence against the latter interpretation, and instead in favor of model misspecification from omitting the dynamic effect of minimum wages. First, they add leading minimum wage effects to the model. These effects are small and insignificant, and do not change the estimated main effect appreciably, suggesting that "if preexisting underlying trends are in fact different between states, they are not different by very much and are unlikely to be a key driver of the overall result” (p. 513). Second, they estimate long-difference specifications over different numbers of periods. If the minimum wage effect grows over time, as in equation (10), then the long-difference estimate should grow with the length of the difference (although perhaps leveling out as a new equilibrium is reached). This is exactly what Meer and West find, with a small and insignificant -0.02 elasticity for a one-year first difference, growing to (and stabilizing at) an elasticity of around -0.05 as the differences get longer. ${ }^{39}$ Finally, they estimate distributed lag estimates that show that, indeed,

\footnotetext{
${ }^{39}$ Moreover, when they then add state-specific time trends to these models, the long-difference estimates are
} 
contemporaneous minimum wage effects are small, but the lags cumulate to a larger effect.

The evidence in Meer and West (2016) is a departure from the larger literature in two dimensions. The first, already discussed, is their focus on dynamic effects. Their evidence points to dynamic effects consistent with “putty-clay” models. Aaronson et al. (2018) generate this type of evidence from a calibrated model for the restaurant industry, but also find evidence consistent with this framework when studying firm entry and exit behavior. Second, Meer and West look at aggregate employment (in three different data sets, one in the paper, and two in on-line appendices), in contrast to the usual focus on lowskill groups or industries. However, in their on-line appendices, they show results for industries in two of the three data sets (for which industry is identified) and find that their evidence is driven more by industries with higher concentrations of low-wage workers (Meer and West, n.d.). Together, this work raises the question of whether the literature should move toward more emphasis on dynamic and hence longer-run models for estimating the employment effects of minimum wages. To be clear, if we find additional evidence of adverse effects on aggregate employment when we look at longer-run models, the policy implications of minimum wages - and especially much higher minimum wages - will likely become much more negative.

\section{Variation in Results across Studies - Economic Factors}

The preceding sections focus on the how econometric methods influence estimated minimum wage effects, in part to help understand the sources of variation in effects across studies. In this section, I turn to the potential role of economic factors in explaining this variation. It is harder to draw specific conclusions, but there are some hints that economic factors may also play a role. A sharper focus on understanding the relationships between estimated employment effects of minimum wages and underlying economic factors may be particularly important in the current and pending high minimum wage environment in the United States, by identifying potential channels that could change employment

sensitive to the length of the difference and become small as the difference length grows. If there were no true minimum wage effect, the estimates with trends should be consistently zero. In contrast, the diminution of the estimated effects is consistent with the trends soaking up the true effect. 
effects at much higher minimum wage levels and suggesting how simply scaling up existing elasticities by larger increases could therefore be misleading.

\section{V.1. The "Bite" of the Minimum Wage}

The issue that is perhaps most important in thinking about the effects of much higher minimum wages, and that may inform the literature more generally, is the "bite" of the minimum wage - i.e., how much the minimum wage binds. This question has received relatively little attention in the research literature.

One type of evidence on a much larger bite comes from an earlier study by Castillo-Freeman and Freeman (1992), who estimated the effects of the minimum wage in Puerto Rico - a U.S. territory that is bound by the U.S. federal minimum wage but has much lower wage levels, and hence where the minimum wage has much more bite. They reported very large aggregate employment effects and particularly adverse effects on low-wage industries, consistent with stronger disemployment effects where the minimum wage binds strongly. This evidence was revisited by Krueger (1995), who found evidence of disemployment effects from time-series data but not cross-industry analyses and concluded that evidence of disemployment effects was fragile. But, surprisingly, to the best of my knowledge the evidence on Puerto Rico has not been revisited. ${ }^{40}$

Neumark and Wascher (2002) take a different approach, adopting techniques from the market disequilibrium literature (applied to labor markets in, e.g., Rosen and Quandt, 1978). They specify a labor demand and labor supply curve and fit a model that estimates the parameters of these curves as well as the probability that an observation is on the demand curve (the short side of the market when, in the standard model, the minimum wage is set too high), or instead at market equilibrium. The estimates of

\footnotetext{
${ }^{40}$ Of course, evidence for one jurisdiction suffers from the absence of a control group - the same concern regarding the earlier time-series evidence for the United States that fueled the interest in minimum wage research using the cross-state variation in state minimum wages that emerged in the late 1980s (and which motivated the cross-industry analysis in the two Puerto Rico studies). The same challenge arises in estimating minimum wage effects in European and other countries with only a national minimum wage. As a consequence of this problem, research on European countries often distinguishes between areas or industries strongly affected by a minimum wage increase and areas or industries not so much affected, with the latter serving as controls for shocks potentially correlated with minimum wages. For example, recent research on the implementation of Germany's new minimum wage focuses on regional variation in the bite of the minimum wage - which was much greater, generally, in formerly East Germany (e.g., Caliendo et al., 2018).
} 
this model are used to compute these probabilities for samples and data used in other studies, asking whether the absence of minimum wage effects (in particular, in Card (1992a and 1992b)) could be attributable to minimum wages being largely non-binding. ${ }^{41}$

However, the approach is based on homogeneous labor, and as such misses what is likely the key issue regarding much higher minimum wages - how the effect changes as the share of workers affected increases. Card's (1992a) approach of specifying the minimum wage variable as the fraction affected by given minimum wage increases, rather than the minimum wage level or its ratio relative to a measure of mean or median wages, may be more useful for projecting the effects of much higher minimum wages, especially if we think we can reliably capture potential non-linearities in the effect of the fraction affected. On the other hand, Baskaya and Rubinstein (2015) suggest that this kind of fraction affected variable is particularly prone to endogeneity with respect to local labor market shocks, and is procyclical and hence leads to bias against finding a disemployment effect. Thus, incorporation of measures of the bindingness of minimum wages may not be straightforward.

Of course, the fraction-affected approach (putting aside endogeneity concerns) would still run into problems in projecting the effects of minimum wages well outside the range of sample variation. However, in very recent years, variation in minimum wages across states has become sufficiently strong that it should be possible, using recent data, to start to obtain more reliable estimates of the effects of minimum wages that bind for a much larger share of workers. Still, the highest minimum wages have been applied in higher-wage states, leaving extrapolation to lower-wage states more problematic.

A different perspective on the bite of the minimum wage that has been explored in recent work is for how long firms expect a minimum wage increase to raise the relative cost of low-skilled labor. This issue has been highlighted by Sorkin (2015), who notes that firms may have reasonably expected the kind of non-indexed, often infrequent minimum wage increases enacted in the United States to be offset by

\footnotetext{
${ }^{41}$ A second model introduced the three regimes in the textbook "company town” monopsony model - the marginal cost of labor curve, the labor supply curve, and the labor demand curve, and found some evidence that the monopsony model fits the data better - although the textbook monopsony model is a far less plausible depiction of labor markets than more modern monopsony models based on search (Manning, 2005).
} 
rising nominal wages (and prices) over time, reducing the incentive for firms to invest in alternative production technologies that economize on low-skilled labor. In contrast, indexed minimum wages, which are becoming increasingly common in American states, ${ }^{42}$ may generate more adverse longer-run employment effects for low-skilled workers. Recent evidence consistent with stronger disemployment effects of indexed minimum wages is reported in Brummund and Strain (2016). Much larger minimum wage increases, especially in a low-inflation environment, could well be perceived by firms as creating large, longer-term relative increases in the cost of low-skilled labor, even aside from indexation.

\section{V.2. Affected Workers}

Closely related to the question of the bite of the minimum wage is the extent to which studies identify the effects of minimum wages on affected workers. Understanding how minimum wages impact the employment of the most directly affected workers is a substantively important policy question, since these are the workers the policy is intended to help. Minimum wage-employment elasticities for teenagers or other low-skill groups are often characterized as "small” or “modest." This is often a vague characterization but is intended to suggest that the net benefits for affected workers must be large. I believe that the most concrete statement of this view is in Freeman (1996). He first notes that "[I]f the elasticity of demand for minimum wage workers exceeds one [in absolute value], the minimum wage will reduce rather than increase the share of earnings going to the low-paid” (p. 641, italicized text added). However, he goes on to state that "No study in the United States or the United Kingdom has found that increases in minimum wages reduce total employment with an elasticity near unity” (p. 642). It is true that much of debate in the literature - in the United States in particular - is about whether the elasticity is zero, or instead in a range of perhaps -0.1 to -0.2 . Freeman's suggestion is that because the latter estimates are well below 1 , the earnings of affected workers, on the whole, will rise substantially when the minimum wage is increased.

But the fact that the existing research often does not focus solely on affected workers means that the elasticity of income of affected workers with respect to the minimum wage must be larger in absolute

\footnotetext{
42 See http://www.ncsl.org/research/labor-and-employment/state-minimum-wage-chart.aspx (viewed June 13, 2018).
} 
value than is implied by the kinds of employment elasticities that dominate the literature. To illustrate, we can simplify and write the minimum wage elasticity estimated for all teenagers (the most common type of estimate) as a weighted average of the elasticity for teenagers directly affected by a change in the minimum wage and the elasticity for teenagers currently earning above the minimum wage, or:

$$
\mathrm{e}=\mathrm{e}^{\mathrm{A}} \cdot \mathrm{p}^{\mathrm{A}}+\mathrm{e}^{\mathrm{NA}} \cdot\left(1-\mathrm{p}^{\mathrm{A}}\right)
$$

where $\mathrm{e}$ is the estimated elasticity for teenagers as a whole, $\mathrm{e}^{\mathrm{A}}$ and $\mathrm{e}^{\mathrm{NA}}$ are the minimum wage elasticities for affected and unaffected teens, and $\mathrm{p}^{\mathrm{A}}$ is the proportion directly affected by the change in the minimum wage. If we assume that the elasticity for unaffected workers is zero, then the minimum wage elasticity for affected teens $\left(\mathrm{e}^{\mathrm{A}}\right)$ can be written:

$$
\mathrm{e}^{\mathrm{A}}=\mathrm{e} / \mathrm{p}^{\mathrm{A}}
$$

It follows that the minimum wage-employment elasticity for affected teenage workers is greater than the employment elasticity estimated for teenagers as a whole.

In addition, the estimated employment elasticity from the usual minimum wage study will tend to understate the employment elasticity of demand for affected workers because the size of the average wage increase associated with a higher minimum wage will be smaller than the minimum wage increase itself, given that some affected workers already earn more than the old minimum wage. Letting $\Delta \mathrm{W}^{\mathrm{A}}$ denote the average wage change of those workers whose wages are directly affected by the change in the minimum wage, and $\triangle \mathrm{MW}$ the legislated increase, the relevant demand elasticity for affected workers (that is, the elasticity with respect to the induced change in their wage) is

$$
\mathrm{e}^{\mathrm{A}}=\left(\mathrm{e} / \mathrm{p}^{\mathrm{A}}\right) /\left(\Delta \mathrm{W}^{\mathrm{A}} / \Delta \mathrm{MW}\right)
$$

Given that $\left(\Delta \mathrm{W}^{\mathrm{A}} / \Delta \mathrm{MW}\right)<1$, the elasticity in equation (14) clearly gets blown up to some extent. The possibility that the employment elasticity for affected worker exceeds -1 is consistent with the evidence from Seattle showing average earnings declines (Jardim et al., 2017). And as noted earlier, Clemens and Wither (2016) estimate an elasticity of -0.97; because they focus on directly affected workers, e and $\mathrm{e}^{\mathrm{A}}$ may be quite close, and $\Delta \mathrm{W}^{\mathrm{A}}$ may be closer to $\Delta \mathrm{MW}$.

Thus, empirical research providing a tighter link between workers affected by the minimum wage 
and the employment effects they experience can sharpen our understanding of the policy implications of higher minimum wages. Neumark and Wascher (2007), in their narrative review of minimum wage research on employment effects since the early 1990s, argued that studies that focused on the least-skilled workers tended to find the sharpest evidence of disemployment effects. However, this argument was based on a qualitative assessment of the evidence across studies, rather than systematic empirical evidence comparing studies. More systematic evidence would be useful.

The most common group considered in studies of the employment effects of minimum wages is teenagers. This is a logical group to study, as teenagers generally earn very low wages because of their low skills and represent a vastly disproportionate share of minimum wage workers. ${ }^{43}$ However, with the rich microdata now available to labor economists, it is possible to focus directly on workers affected by the minimum wage. Examples of minimum wage studies that try to identify impacts on affected workers, based on their wages, include Neumark et al. (2004) and, more recently, Clemens and Wither (2016).

One limitation of this approach, however, is that we cannot as easily classify non-workers as affected or not, because we do not observe their wages, which can lead us to miss the effects of minimum wages on transitions from non-employment to employment. Changes in the rate of entry into employment, however, could be a quite important channel of employment adjustments. First, low-skill workers have very high turnover. ${ }^{44}$ Second, there is evidence from data on worker flows that minimum wages lower the rate at which workers separate from firms and lower the rate at which workers are hired (Dube et al., 2016; Gittings and Schmutte, 2016; Gopalan et al., 2018). ${ }^{45}$ Thus, ignoring the effects of minimum wages in reducing the flows of workers into jobs may well miss a potentially important channel by which higher minimum wages reduce employment of low-skilled workers.

\footnotetext{
${ }^{43}$ For example, in 2016, teens were nearly 21 percent of workers paid hourly whose wages were at or below the federal minimum wage, but less than 6 percent of the total of workers paid hourly. (See https://www.bls.gov/opub/reports/minimum-wage/2016/home.htm, viewed May 10, 2017.) The representation of teens among minimum wage workers would, of course, decline at much higher minimum wages, and is likely to be lower in states with higher minimum wages.

${ }^{44}$ See Choi and Fernández-Blanco (2016).

${ }^{45}$ Like with the general literature on employment effects, there is conflicting evidence on whether or not the relative magnitudes of these two effects lead, on net, to employment declines. Also, note that Kabátek's (2015) evidence for the Netherlands differs in finding a separation effect of minimum wage increases at specific ages.
} 
One can of course study the effects of minimum wages on transitions from non-employment to employment (see Clemens and Wither, 2017). But our ignorance of likely offer wages for non-employed workers is a challenge. Selection-type models that predict wages for the low-skilled, non-employed could in principle be used, although given the relatively low explanatory power of wage regressions, it seems unlikely that such methods would accurately identify the lowest-wage workers. Longer-term panel data can tell us something about wages workers earned on previous jobs, which could potentially prove useful, although that information, too, may be available only for a subset of currently non-employed workers.

There may be other dimensions that influence how likely minimum wages are to affect certain groups of workers. For example, Lordan and Neumark (2018) study the effects of minimum wages on low-skill workers in jobs that are more easily automated, and find adverse employment effects for older workers, and for workers in some industries where we tend not to think minimum wages have much effect, like manufacturing.

Understanding how estimated minimum wage effects depend on variation in the identification of the impact from affected workers, and which affected workers, may also help clarify the underlying economics. For example, if the evidence of disemployment effects really is stronger and more robust when studies focus on directly affected workers, this would bolster the predictions of the standard neoclassical model's prediction of job loss from substitution away from the least-skilled workers (as well as scale effects), and also help explain why some studies find weaker evidence of job loss (for example, in studies that focus on industries that pay low average wages but have a good share of higher-wage workers). In contrast, if there is an absence of a consistent pattern of larger disemployment effects when these effects are estimated for the lowest-skilled workers whose wages are pushed up by minimum wages, the neoclassical model's prediction would be harder to sustain.

In addition, sharper evidence on how minimum wage effects vary depending on the extent to which effects are identified from affected workers may give us a better handle on predicting effects of much higher minimum wages that will affect more workers. ${ }^{46}$ I view this as a critical challenge. At a

\footnotetext{
${ }^{46}$ Still, a potential difficulty in predicting such effects is that the impacts on affected workers may also depend on
} 
minimum, labor economists should be using the available microdata to try to identify skill and demographic groups likely to be affected by minimum wages, moving beyond just teenagers or workers in low-wage industries. ${ }^{47}$ And it may be particularly useful to explore using panel data with wage information, or other methods, to directly identify workers and non-workers most affected by higher minimum wages and how minimum wage increases affect their flows into and out of employment. One potentially large-scale source of data that could be used is Unemployment Insurance records for the subset of states that report quarterly hours as well as earnings, from which wages can then be estimated conditional on states making the data available to researchers, like in the recent study of the Seattle minimum wage. ${ }^{48}$

\section{V.3. Labor-Labor Substitution}

Studies that include both affected and unaffected workers can do even more to mask disemployment effects of minimum wages if there is labor-labor substitution. In a model with workers of different skill levels, a minimum wage that is binding for some workers is likely to generate some substitution towards higher-skill workers. One implication is that evidence on the employment effects of minimum wages that combine negative employment effects for the least-skilled with positive employment effects for those who benefit from labor-labor substitution will understate the net effects on the first group. A second implication is that such evidence will obscure the positive impacts on those workers who benefit from labor-labor substitution.

There is some evidence of labor-labor substitution, from research on both minimum wages (e.g., Neumark and Wascher, 2003; Clemens et al., 2018) and on living wages (Fairris and Bujunda, 2008). ${ }^{49}$

the share of workers affected, as we might anticipate that firms find it easier to make adjustments other than employment levels for small changes in minimum wages than for large changes in minimum wages. That is, there can be nonlinear effects of the share affected by minimum wage increases.

${ }^{47}$ For example, Monras (2015) presents some evidence of negative employment effects on the share of employment or full-time employment among those with a high school degree or less, without regard to age. (This is apparent only from de-trended estimates, using a method described earlier.)

${ }^{48}$ See Jardim et al. (2017).

${ }^{49}$ Living wages were a policy that arose in many cities (and other local jurisdictions) in the United States in the mid1990s. Living wages typically imposed wage floors much higher than minimum wages but limited to much narrower sets of workers (city contractors, and firm receiving financial assistance from cities). For details and recent evidence, see Neumark et al. (2012). 
But there is virtually no research that tries to use information on workers across a larger swath of the skill distribution to provide a fuller accounting of who gains and who loses from a higher minimum wage. Neumark et al. (2004) estimate wage, hours, employment, and income effects at different points of the wage distribution and find some evidence of hours increases a bit above the minimum, but also of wage declines (which could be attributable to labor supply increases, or to scale effects outweighing substitution effects).

Note, also, that this kind of evidence is likely to be informative about the effects of much higher minimum wages. The ability to substitute away from labor whose price is directly increased by the minimum wage seems likely to be diminished as the minimum wage affects the wages of a larger share of workers. At the same time, the larger price increases implied by less labor-labor substitution imply may make it more likely that scale effects become important.

\section{V.4. Predictions from Monopsony Models}

Finally, spurred in part by studies that do not find evidence of disemployment effects of minimum wages, and occasionally even find positive effects, minimum wage researchers have sometimes appealed to monopsony search models as a better characterization of the low-skill labor market (beginning with Card and Krueger, 1995, and developed to a much greater extent in Manning, 2005). Understanding the underlying model is obviously central to identifying economic factors that can explain variation in the employment effects of minimum wages across studies.

Search models can, indeed, predict a positive effect of minimum wages over some range. This was first pointed out in Stigler (1946), albeit in the case of a textbook single-buyer monopsony model. Brown et al. (2014) show in a fairly simple way how this result emerges in a modern search model that instead generates rising marginal costs of labor from frictions.

It is possible that search-monopsony models can account for the variation in estimated employment effects of minimum wages across studies. However, establishing this requires much more than noting that these models are consistent with such variation. As I have emphasized above, there are many reasons to expect variation in employment effects when the neoclassical model characterizes low- 
skill labor markets. I would find more convincing the claim that monopsony models can account for the variation in estimates - and therefore also the implication that minimum wages can sometimes increase employment - if there were evidence that directly tied variation in minimum wage effects to the predictions of these models. Christl et al. (forthcoming) report evidence of a nonlinear minimum wage effect - first increasing and then decreasing - which is potentially consistent with these models. But evidence on more direct implications of these models would be more compelling. In particular, can we find evidence that the studies that find zero or even positive effects do this in settings where monopsony search models predict positive effects, and similarly find negative effects when the models predict negative effects - based, perhaps, on variation in the extent of frictions, in the level of the minimum wage, in the time frame (short- versus longer-run), etc.?

Of course, by the same token, the neoclassical model should not simply be taken as the default in the absence of more compelling evidence that search-monopsony models can explain the variation in employment effects across studies. In line with much of the discussion above, the neoclassical characterization of low-skill labor markets would be bolstered by more convincing evidence that variation across studies in estimated employment effects can be explained in the context of this model.

There is a direct way in which more evidence on the appropriate model may help in predicting the effects of much larger minimum wage increases. While the empirical methods used in past research on the employment effects of minimum wages are useful in studying the effects of past increases, a wellknown limitation of these reduced-form methods is that they are less valuable in predicting the effects of different kinds of policy changes than are present in past data. Although large minimum wage increases naturally share some features with smaller increases, some of the considerations discussed above - such as the likely closing off of other margins of adjustment to higher minimum wages - suggest that structural models may have some value in projecting the effects of large minimum wage increases. One example is the calibrated model in Reich et al. (2015), although these authors have not provided, to the best of my knowledge, a detailed explication of the model they use, and have focused more on the predictions it generates. One problem, however, at least with models that are calibrated rather than estimated, is that 
the evidence on past minimum wage increases needed to calibrate the model is contested. ${ }^{50}$ It would therefore surely be useful to gauge the sensitivity of these kinds of exercises to calibrations that reflect the larger employment elasticities that many recent studies find, and perhaps even more useful to push this approach further, including estimation of structural models that could at least provide complementary evidence on predicted effects of out-of-sample minimum wage increases.

\section{Conclusions, and Questions for a Continuing Research Agenda on the Employment Effects of}

\section{Minimum Wages}

Although this paper is not intended as a review and assessment of all the evidence on minimum wages, it is nonetheless useful to summarize the key conclusions that one can, in my view, draw from the literature on the employment effects of minimum wages.

First, the evidence on the disemployment effect of minimum wages is contested, and there clearly are studies that find no employment effect - both in the United States and in other countries. However, the preponderance of evidence indicates that minimum wages reduce employment of the least-skilled workers. Earlier estimates suggested an "elasticity" of about -0.1 to -0.2 . Many estimates are still in this range, some are closer to zero, and some are larger. To be clear, some researchers may have reason to put more store in the types of estimates that tend to find no employment effects - typically the research designs that I have labeled “close controls.” I have indicated reasons I am somewhat skeptical of these designs, but also indicated that the jury is still out. More definitively, though, it is indisputable that there is a body of evidence pointing to job losses from higher minimum wages. Characterizations of the literature as providing no evidence of job loss are simply inaccurate. ${ }^{51}$

Second, there are two kinds of changes in minimum wages about which we know a lot less. The

\footnotetext{
50 This is evidenced, for example, by the numerous simulation studies Michael Reich and co-authors have written, appealing to a "structural model” to project the effects of proposed high minimum wage increases in various cities. The studies typically project little if any job loss. For example, Reich et al. (2016) predict that a \$15 minimum wage in San Jose and Santa Clara Counties (California), phased in by 2019, would cost 960 jobs in San Jose, and only 80 fewer jobs over the broader region. However, as they point out, their model is calibrated to "be consistent with the very small effects that researchers find for the smaller pre-2015 increases in federal and state minimum wages” (Reich et al., 2016, p. 20). Clearly this view of the evidence is not shared by everyone.

${ }^{51}$ For example, Paul Krugman (2015) has claimed "There's just no evidence that raising the minimum wage costs jobs, at least when the starting point is as low as it in in modern America.”
} 
first change is the adoption of much higher minimum wages - as is happening in the United States with serious movement towards a $\$ 15$ minimum. There is a great deal of uncertainty about the employment effects of a \$15 minimum wage. One thing we do know is that it would impact far more workers than the current minimum wage, especially in lower-wage states and lower-wage areas of most states. More speculatively, my sense is that the costs of a much higher minimum wage are likely to be understated by simply scaling up the effects based on employment elasticities in the existing literature, because the much higher share of workers affected will reduce employers’ ability to partially offset minimum wage increases by changes in margins other than employment.

The second kind of change about which we know relatively little concerns the introduction of a new minimum wage - like in Germany. There is some evidence from the introduction of a new minimum wage in the United Kingdom. Some of this evidence points to job loss, but the evidence is mixed. And, of course, the institutional setting is not the same.

Finally, given that the key goal of this paper is to identify important questions to improve our understanding of the employment effects of minimum wages, I conclude by listing what I view as the most productive questions to pursue, based on the research I have reviewed:

1. Why do identification strategies based on close geographic controls tend to find weak or no evidence of disemployment effects of minimum wages, in contrast to other methods?

2. Which type of identification strategy should be viewed as most convincing, and why should conflicting evidence from other strategies be viewed more skeptically?

3. Can we develop a better understanding of what determines minimum wage policy, and can this help us narrow the set of compelling strategies for identifying the employment effects of minimum wages?

4. To what extent can theoretical modeling, such as search models, help us understand variation in results across identification strategies?

5. How can we move beyond the inclusion of little-understood trends in our models of employment effects, to capture influences predicted by our models that can be measured in the data, or to 
refine estimates when we are limited to including trends in some way?

6. Should we move away from models focusing on short-term effects of the minimum wage on the level of low-skilled employment, and towards a focus on longer-term dynamic effects?

7. If we move to dynamic models, what does the evidence say, and do we really find robust evidence of effects of minimum wages on aggregate employment?

8. How can we generate more systematic evidence on the relationship between the bite of the minimum wage and estimated employment effects?

9. Does variation across studies in the focus on affected workers help explain variation in results, and how can we use longitudinal data on workers to better isolate affected workers?

10. Does labor-labor substitution help explain variation in estimated employment effects across studies?

11. Can monopsony in labor markets really account for the variation in estimated employment effects across studies?

12. Can we use evidence on the bite of the minimum wage, the share of affected workers, labor-labor substitution, and monopsony models to help predict the effects of much larger minimum wage increases? 


\section{References}

Aaronson, Daniel, Eric French, Isaac Sorkin, and Ted To. 2018. "Industry Dynamics and the Minimum Wage: A Putty-Clay Approach.” International Economic Review, Vol. 59, No. 1, February, pp. 51-84.

Abadie, Alberto, Alexis Diamond, and Jens Hainmueller. 2010. "Synthetic Control Methods for Comparative Case Studies: Estimating the Effect of California's Tobacco Control Program.” Journal of the American Statistical Association, Vol. 105, No. 490, February, pp. 493-505.

Addison, John T., McKinley L. Blackburn, and Chad D. Cotti. 2013. "Minimum Wage Increases in a Recessionary Environment.” Labour Economics, Vol. 23, August, pp. 30-9.

Allegretto, Sylvia A., Arindrajit Dube, and Michael Reich. 2011. "Do Minimum Wages Really Reduce Teen Employment? Accounting for Heterogeneity and Selectivity in State Panel Data.” Industrial Relations, Vol. 50, No. 2, April, pp. 205-40.

Allegretto, Sylvia A., Arindrajit Dube, Michael Reich, and Ben Zipperer. 2017. "Credible Research Designs for Minimum Wage Studies.” Industrial and Labor Relations Review, Vol. 70, No. 3, May, pp. 559-92.

Baskaya, Yusuf Soner, and Yona Rubinstein. 2015. "Using Federal Minimum Wages to Identify the Impact of Minimum Wages on Employment and Earnings across U.S. States.” Unpublished paper.

Belman, Dale, and Paul J. Wolfson. 2016. "15 Years of Research on U.S. Employment and the Minimum Wage.” Tuck School of Business Working Paper No. 2705499.

Belman, Dale, and Paul J. Wolfson. 2014. What Does the Minimum Wage Do? Kalamazoo, MI: Upjohn Press.

Bohn, Sarah, Magnus Lofstrom, and Steven Raphael. 2014. "Did the 2007 Legal Arizona Workers Act Reduce the State's Unauthorized Immigrant Population?” Review of Economics and Statistics, Vol. 96, No. 2, May, pp. 258-69.

Brown, Charles, Curtis Gilroy, and Andrew Kohen. 1982. "The Effect of the Minimum Wage on Employment and Unemployment.” Journal of Economic Literature, Vol. 20, No. 2, June, pp. 487528.

Brown, Alessio. J. G., Christian Merkl, and Dennis J. Snower. 2014. "The Minimum Wage from a TwoSided Perspective.” Economics Letters, Vol. 124, pp. 389-91.

Brummund, Peter, and Michael R. Strain. 2016. "Real and Permanent Minimum Wages.” AEI Economics Working Paper 2016-06.

Cadena, Brian C. 2014. "Recent Immigrants as Labor Market Arbitrageurs: Evidence from the Minimum Wage.” Journal of Urban Economics, Vol. 80, March, pp. 1-12.

Caliendo, Marco, Alexandra Fedorets, Malte Preuss, Carsten Schroeder, and Linda Wittbrodt. 2018. “The Short-Run Employment Effects of the German Minimum Wage Reform.” Labour Economics, Vol. 53, pp. 46-62.

Campolieti, Michele, Tony Fang, and Morley Gunderson. 2005. “Minimum Wage Impacts on Youth Employment Transitions, 1993-1999.” Canadian Journal of Economics. Vol. 38, No. 1, pp. 81-104.

Campolieti, Michele, Morley Gunderson, and Chris Riddell. 2006. "Minimum Wage Impacts from a Prespecified Research Design: Canada 1981-1997.” Industrial Relations, Vol. 45, No. 2, pp. 195-216.

Card, David. 1992a. "Using Regional Variation in Wages to Measure the Effects of the Federal Minimum Wage.” Industrial and Labor Relations Review, Vol. 46, No. 1, October, pp. 22-37.

Card, David. 1992b. "Do Minimum Wages Reduce Employment? A Case Study of California, 19871989.” Industrial and Labor Relations Review, Vol. 46, No. 1, October, pp. 38-54.

Card, David, and Alan B. Krueger. 1995. Myth and Measurement: The New Economics of the Minimum Wage. Princeton, N.J.: Princeton University Press.

Card, David, and Alan B. Krueger. 1994. "Minimum Wages and Employment: A Case Study of the FastFood Industry in New Jersey and Pennsylvania.” American Economic Review, Vol. 84, No. 4, September, pp. 772-93.

Castillo-Freeman, Alida, and Richard B. Freeman. 1992. "When the Minimum Wage Really Bites: The Effect of the U.S.-Level Minimum on Puerto Rico.” In George. J. Borjas and Richard B. Freeman, Eds., Immigration and the Workforce: Economic Consequences for the United States and Source 
Areas. Chicago, IL: University of Chicago Press, pp. 177-211.

Cengiz, Doruk, Arindrajit Dube, Attila Lindner, and Ben Zipperer. 2017. "The Effect of Minimum Wages on the Total Number of Jobs; Evidence from the United States Using a Bunching Estimator.” Unpublished paper, http://sole-jole.org/17722.pdf (viewed June 30, 2018).

Choi, Sekyu, and Fernández-Blanco, Javier. 2016. “A Note on U.S. Turnover.” Unpublished paper.

Christl, Michael, Monika Köppl-Turnya, and Dénes Kucsera. "Revisiting the Employment Effects of Minimum Wages in Europe.” Forthcoming in German Economic Review.

Clemens, Jeffrey, Lisa B. Kahn, and Jonathan Meer. 2018. "Impacts of the Minimum Wage on Skill Requirements: Evidence from Vacancy Postings.” Discussion paper, Yale University.

Clemens, Jeffrey, and Michael R. Strain. "The Short-Run Employment Effects of Recent Minimum Wage Changes: Evidence from the American Community Survey.” Forthcoming in Contemporary Economic Policy.

Clemens, Jeffrey, and Michael Wither. 2017. “Additional Evidence and Replication Code for Analyzing the Effects of Minimum Wage Increases Enacted During the Great Recession.” ESSPRI Working Paper Series, Paper \#20173.

Clemens, Jeffrey, and Michael Wither. 2016. "The Minimum Wage and the Great Recession: Evidence of Effects on the Employment and Income Trajectories of Low-Skilled Workers.” Unpublished paper.

Colangelo, Kyle, and Matthew Harding. In progress. "How Much Should We Trust Fixed Effects in Long Term Program Evaluation?”

de Blasio, Guido, and Samuele Poy. 2017. "The Impact of Local Wage Regulation on Employment: A Border Analysis from Italy in the 1950s.” Journal of Regional Science, Vol. 57, No. 1, January, pp. 48-74.

de Linde Leonard, Megan, T.D. Stanley, and Hristos Doucouliagos. 2014. "Does the UK Minimum Wage Reduce Employment? A Meta-Regression Analysis.” British Journal of Industrial Relations, Vol. 52, No. 3, pp. 499-520.

Dickens, Richard, Stephen Machin, and Alan Manning. 1999. “The Effects of Minimum Wages on Employment: Theory and Evidence.” Journal of Labor Economics, Vol. 17, No. 1, pp. 1-22.

Dolado, Juan, Francis Kramarz, Stephen Machin, Alan Manning, David Margolis, Coen Teulings, Gilles Saint-Paul, and Michael Keen. 1996. "The Economic Impact of Minimum Wages in Europe.” Economic Policy, Vol. 11, No. 23, pp. 317-72.

Dube, Arindrajit, T. William Lester, and Michael Reich. 2016. "Minimum Wage Shocks, Employment Flows, and Labor Market Frictions.” Journal of Labor Economics, Vol. 34, No. 3, July, pp. 663-704.

Dube, Arindrajit, T. William Lester, and Michael Reich. 2010. "Minimum Wage Effects across State Borders: Estimates Using Contiguous Counties.” Review of Economics and Statistics, Vol. 92, No. 4, November, pp. 945-64.

Dube, Arindrajit., and Ben Zipperer. 2015. "Pooling Multiple Case Studies using Synthetic Controls: An Application to Minimum Wage Policies.” IZA Discussion Paper No. 8944.

Even, William E., and David A. Macpherson. 2017. “California Dreamin’ of Higher Wages.” Employment Policies Institute, https://www.epionline.org/wpcontent/uploads/2017/12/EPI_CaliforniaDreamin_final.pdf (viewed June 24, 2018).

Fairris, David, and Leon Fernandez Bujunda. 2008. “The Dissipation of Minimum Wage Gains for Workers through Labor-Labor Substitution: Evidence from the Los Angeles Living Wage Ordinance.” Southern Economic Journal, Vol. 75, No. 2, October, pp. 473-96.

Freeman, Richard B. 1996. “The Minimum Wage as a Redistributive Tool.” Economic Journal, Vol. 106, No. 436, May, pp. 639-49.

Galindo-Rueda, Fernando, and Sonia Pereira. 2004. "The Impact of the National Minimum Wage on British Firms.” Final (Draft) Report to the Low Pay Commission on the Econometric Evidence from the Annual Respondents Database.

Gittings, R. Kaj, and Ian M. Schmutte. 2016. "Getting Handcuffs on an Octopus: Minimum Wages, Employment, and Turnover.” Industrial and Labor Relations Review, Vol. 69, No. 5, October, pp. 1133-70.

Gopalan, Radhakrishnan, Barton Hamilton, Ankit Kalda, and David Sovich. 2018. "State Minimum Wage 
Changes and Employment: Evidence from One Million Hourly Wage Workers.” Unpublished paper, Washington University.

Griliches, Zvi. 1979. "Sibling Models and Data in Economics: Beginnings of a Survey.” Journal of Political Economy, Vol. 87, No. 5, Part 2, October, pp. S37-S64.

Hoffman, Saul D. 2016. “Are the Effects of Minimum Wage Increases Always Small? A Reanalysis of Sabia, Burkhauser, and Hansen.” Industrial and Labor Relations Review, Vol. 69, No. 2, March, pp. 295-311.

Holtz-Eakin, Douglas, and Ben Gitis. 2015. “Counterproductive: The Employment and Income Effects of Raising America’s Minimum Wage to \$12 and to \$15 per Hour.” American Action Forum, July 27, https://www.americanactionforum.org/research/counterproductive-the-employment-and-incomeeffects-of-raising-americas-min/ (viewed June 24, 2018).

Jardim, Ekaterina, Mark C. Long, Robert Plotnick, Emma van Inwegen, Jacob Vigdor, and Hilary Wething. 2017. "Minimum Wage Increases, Wages, and Low-Wage Employment: Evidence from Seattle.” NBER Working Paper No. 23532.

Jardim, Ekaterina, Mark C. Long, Robert Plotnick, Emma van Inwegen, Jacob Vigdor, and Hilary Wething. In progress. "The Extent of Local Minimum Wage Spillovers.”

Kabátek, Jan. 2015. "Happy Birthday, You're Fired! The Effects of Age-Dependent Minimum Wage on Youth Employment Flows in the Netherlands.” IZA Discussion Paper No. 9528.

Krueger, Alan B. 1995. "The Effect of the Minimum Wage When It Really Bites: A Reexamination of the Evidence from Puerto Rico.” Research in Labor Economics, Vol. 14, pp. 1-22.

Krugman, Paul. 2015. "Liberals and Wages.” New York Times, July 17, https://www.nytimes.com/2015/07/17/opinion/paul-krugman-liberals-and-wages.html.

Kuehn, Daniel. 2016. "Spillover Bias in Cross-Border Minimum Wage Studies: Evidence from a Gravity Model.” Journal of Labor Research, Vol. 37, No. 4, December, pp. 441-59.

Liu, Shanshan, Thomas J. Hyclak, and Krishna Regmi. 2016. "Impact of the Minimum Wage on Youth Labor Markets.” LABOUR, Vol. 30, No. 1, March, pp. 18-37.

Lordan, Grace, and David Neumark. 2018. "People versus Machines: The Impact of Minimum Wages on Automatable Jobs.” Labour Economics, Vol 52, June, pp 40-53.

Machin, Stephen, and Alan Manning. 1994. "Minimum Wages, Wage Dispersion and Employment: Evidence from the UK Wages Councils,” Industrial and Labor Relations Review, Vol. 47, No. 2, pp. 319-29.

Machin, Stephen, Alan Manning, and Lupin Rahman. 2003. "Where the Minimum Wage Bites Hard: Introduction of Minimum Wages to a Low Wage Sector." Journal of the European Economic Association, Vol. 1, No. 1, pp. 154-80.

Manning, Alan. 2005. Monopsony in Motion. Princeton, NJ: Princeton University Press.

McKinnish, Terra, 2017. "Cross-State Differences in the Minimum Wage and Out-of-State Commuting by Low-Wage Workers.” Regional Science and Urban Economics, Vol. 64, May, pp. 137-47.

McVicar, Duncan, Andrew Park, and Seamus McGuinness. 2018. "Exploiting the Irish Border to Estimate Minimum Wage Impacts in Northern Ireland.” IZA Discussion Paper No. 11585.

Meer, Jonathan, and Jeremy West. 2016 "Effects of the Minimum Wage on Employment Dynamics." Journal of Human Resources, Vol. 51, No. 2, pp. 500-22.

Meer, Jonathan, and Jeremy West. n.d. "Online Appendices for Effects of the Minimum Wage on Employment Dynamics.” https://uwpress.wisc.edu/journals/pdfs/JHRv51n02_article08_MeerWest_Appendix.pdf (viewed June 29, 2018).

Monras, Joan. 2015. “Minimum Wages and Spatial Equilibrium: Theory and Evidence.” IZA Discussion Paper No. 9460.

Neumark, David. 2018. "The Employment Effects of Minimum Wages: Some Questions We Need to Answer.” Oxford Research Encyclopedia of Economics and Finance. http://economics.oxfordre.com/view/10.1093/acrefore/9780190625979.001.0001/acrefore9780190625979-e-137 (viewed July 1, 2018).

Neumark, David. 2016. "Policy Levers to Increase Jobs and Increase Income from Work after the Great 
Recession.” IZA Journal of Labor Policy, 5:6 (on-line).

Neumark, David. 2001. "The Employment Effects of Minimum Wages: Evidence from a Prespecified

Research Design.” Industrial Relations, Vol. 40, No. 1, pp. 121-44.

Neumark, David, J.M. Ian Salas, and William Wascher. 2014a. "Revisiting the Minimum Wage-

Employment Debate: Throwing out the Baby with the Bathwater?” Industrial and Labor Relations

Review, Vol. 67, Supplement, pp. 608-48.

Neumark, David, J.M. Ian Salas, and William Wascher. 2014b. "More on Recent Evidence on the Effects of Minimum Wages in the United States.” IZA Journal of Labor Policy, 3:24 (on-line).

Neumark, David, Mark Schweitzer, and William Wascher. 2004. "Minimum Wage Effects Throughout the Wage Distribution.” Journal of Human Resources, Vol. 39, No. 2, Spring, pp. 425-50.

Neumark, David, Matthew Thompson, and Leslie Koyle. 2012. "The Effects of Living Wage Laws on Low-Wage Workers and Low-Income Families: What Do We Know Now?” IZA Journal of Labor Policy, 1:11 (on-line).

Neumark, David, and William Wascher. 2017. "Reply to Credible Research Designs for Minimum Wage Studies.” Industrial and Labor Relations Review, Vol. 70, No. 3, May, pp. 593-609.

Neumark, David, and William Wascher. 2008. Minimum Wages. Cambridge, MA: MIT Press.

Neumark, David, and William L. Wascher. 2007. "Minimum Wages and Employment.” Foundations and Trends in Microeconomics, Vol. 3, Nos. 1-2, pp. 1-182.

Neumark, David, and William L. Wascher. 2004. "Minimum Wages, Labor Market Institutions, and Youth Employment: A Cross-National Analysis.” ILR Review, Vol. 57, No. 2, pp. 223-48.

Neumark, David, and William Wascher. 2003. "Minimum Wages and Skill Acquisition.” Economics of Education Review, Vol. 22, No. 1, February, pp. 1-10.

Neumark, David, and William Wascher. 2002. "State-Level Estimates of Minimum Wage Effects: New Evidence and Interpretations from Disequilibrium Methods.” Journal of Human Resources, Vol. 37, No. 1, Winter, pp. 35-62.

Neumark, David, and William Wascher. 1994. "Employment Effects of Minimum and Subminimum Wages: Reply to Card, Katz, and Krueger.” Industrial and Labor Relations Review, Vol. 47, No. 3, April, pp. 497-512.

Pérez Pérez, Jorge. 2018. “City Minimum Wages.” Unpublished paper, Brown University, http://jorgeperezperez.com/files/Jorge_Perez_JMP.pdf (viewed July 19, 2018).

Pesaran, M. Hashem. 2006. "Estimation and Inference in Large Heterogeneous Panels with a Multifactor Error Structure.” Econometrica, Vol. 74, No. 4, July, pp. 967-1012.

Powell, David. 2016. "Synthetic Control Estimation Beyond Case Studies: Does the Minimum Wage Reduce Employment?” RAND Labor \& Population Working Paper WR-1142.

Reich, Michael. 2016. “A \$15 Wage Won’t Cost New York Jobs.” New York Daily News, March 11, http://www.nydailynews.com/opinion/michael-reich-15-wage-won-cost-new-york-jobs-article1.2560449 (viewed June 24, 2018).

Reich, Michael, Sylvia Allegretto, and Anna Godoey. 2017. “Seattle’s Minimum Wage Experience 201516.” Center for Wage Dynamics Policy Brief, University of California, Berkeley.

Reich, Michael, Ken Jacobs, Annette Bernhardt, and Ian Perry. 2015. “The Proposed Minimum Wage Law for Los Angeles: Economic Impact and Policy Outcomes.” Center on Wage and Employment Dynamics Policy Brief, University of California, Berkeley.

Reich, Michael, Claire Montialoux, Sylvia Allegretto, Ken Jacobs, Annette Bernhardt, and Sarah Thomason. 2016. "The Effects of a \$15 Minimum Wage by 2019 in San Jose and Santa Clara County.” Center on Wage and Employment Dynamics Policy Brief, University of California, Berkeley.

Rosen, Harvey S., and Richard E. Quandt. 1978. "Estimation of a Disequilibrium Aggregate Labor Market.” Review of Economics and Statistics, Vol. 60, No. 3, August, pp. 371-9.

Sabia, Joseph J., Richard V. Burkhauser, and Benjamin Hansen. 2012. "Are the Effects of Minimum Wage Increases Always Small? New Evidence from a Case Study of New York.” Industrial and Labor Relations Review, Vol. 65, No. 2, April, pp. 350-76.

Schmitt, John. 2015. "Explaining the Small Employment Effects of the Minimum Wage in the United 
States.” Industrial Relations, Vol. 54, No. 4, October, pp. 547-81.

Shirley, Peter. "The Response of Commuting Patterns to Cross-Border Policy Differentials: Evidence from the American Community Survey.” Forthcoming in Regional Science and Urban Economics.

Shirley, Peter. 2017. "The Effects of the Minimum Wage on Employment: Evidence from a Hierarchical Bayes Framework.” Unpublished paper.

Slichter, David. 2016. "The Employment Effects of the Minimum Wage: A Selection Ratio Approach to Measuring Treatment Effects.” Unpublished paper.

Sorkin, Isaac. 2015. “Are There Long-Run Effects of the Minimum Wage?” Review of Economic Dynamics, Vol. 18, No. 2, April, pp. 306-33.

Stigler, George J. 1946. “The Economics of Minimum Wage Legislation.” American Economic Review, Vol. 36, No. 3, June, pp. 358-65.

Sturn, Simon. 2018. "Do Minimum Wages Lead to Job Losses? Evidence from OECD Countries on LowSkilled and Youth Unemployment.” ILR Review, Vol. 71, No. 3, pp. 647-75.

Thompson, Jeffrey P. 2009. "Using Local Labor Market Data to Re-examine the Employment Effects of the Minimum Wage.” Industrial and Labor Relations Review, Vol. 62, No. 3, April, pp. 343-66.

Totty, Evan. 2017. "The Effect of Minimum Wages on Employment: A Factor Model Approach.” Economic Inquiry, Vol. 55, No. 4, October, pp. 1712-37.

Zhang, Weilong. 2017. "Distributional Effects of Local Minimum Wage Hikes: A Spatial Job Search Approach.” Unpublished paper, University of Pennsylvania. 
Figure 1: Percent Differences between State and Federal Minimum Wages, 2018

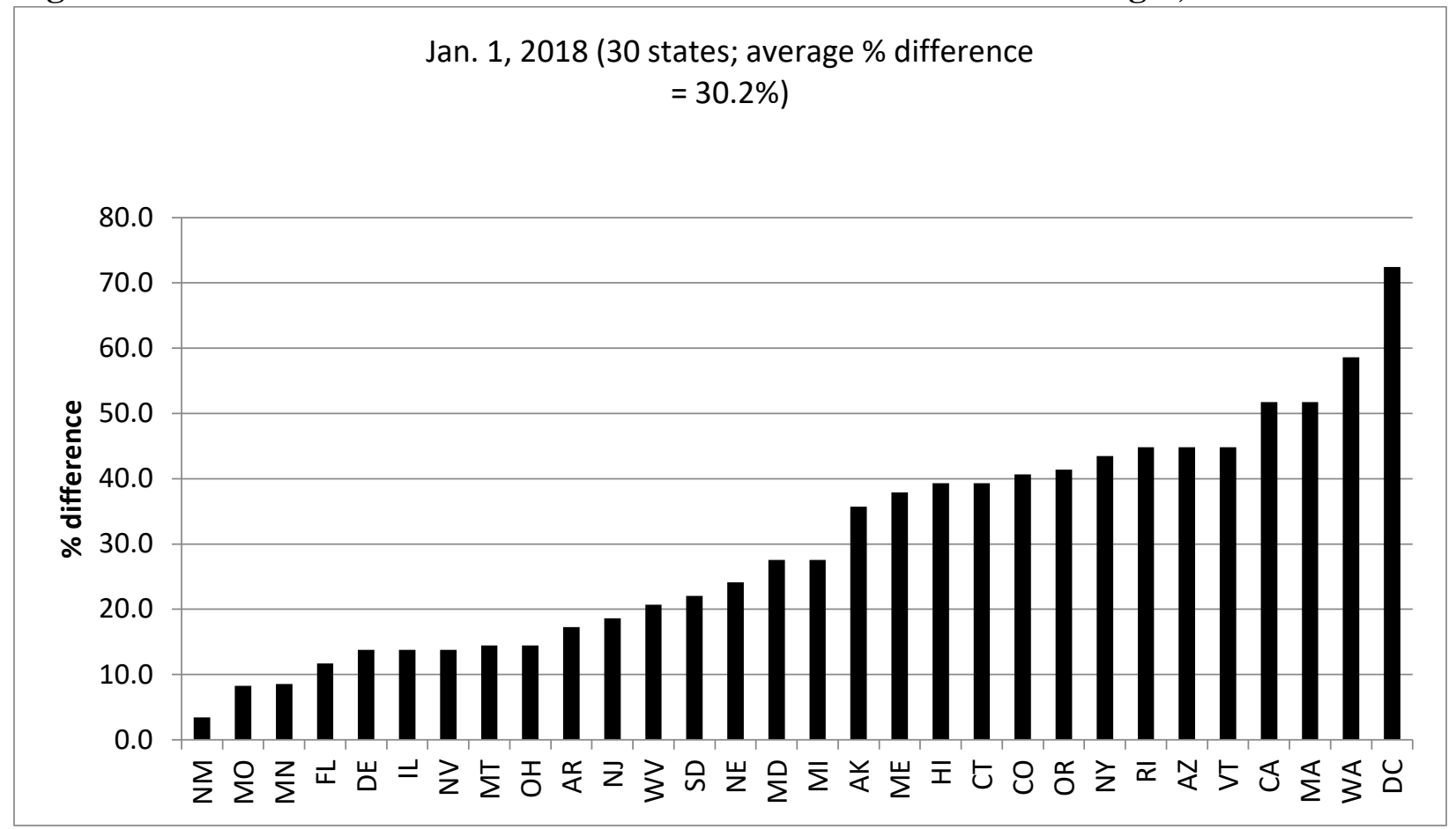


Figure 2: States (and Territories) with Higher vs. Federal Minimum Wage, Jan. 1, 2018

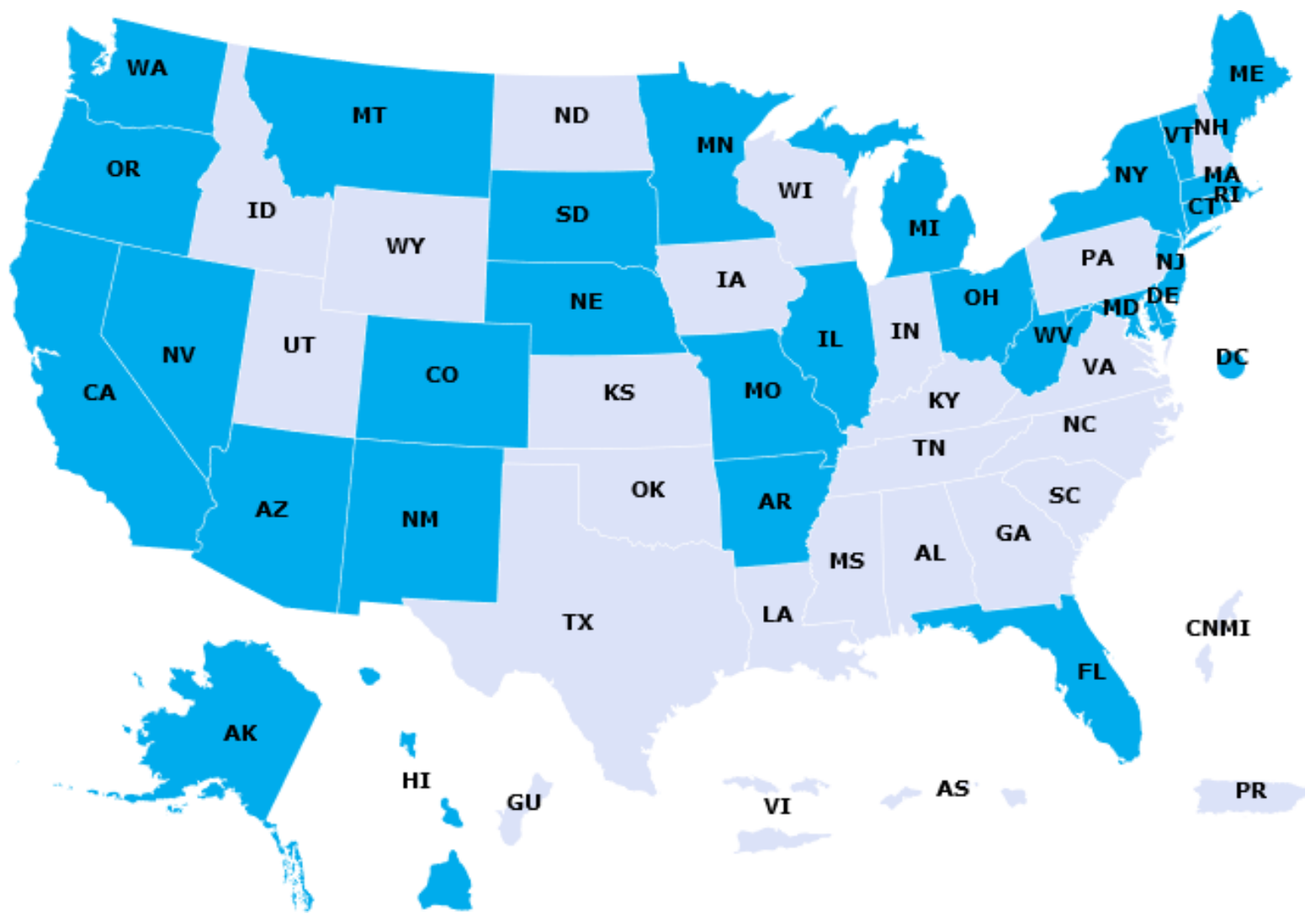

Source: https://www.dol.gov/whd/minwage/america.htm (viewed June 24, 2018). In states shaded light gray, the federal minimum wage prevails for workers covered by the Fair Labor Standard Act. The state minimum wage is higher in the other states. 
Table 1: Recent Estimates of Minimum Wage Effects on Unskilled Employment

\begin{tabular}{|c|c|c|}
\hline Authors & Employment elasticity and groups studied & Data/approach \\
\hline \multicolumn{3}{|c|}{ Geographically-proximate designs } \\
\hline $\begin{array}{l}\text { Dube, Lester, and } \\
\text { Reich (2010) }\end{array}$ & Near zero for teens and restaurant workers. & $\begin{array}{l}\text { Data: Quarterly Census of Employment } \\
\text { and Wages (QCEW). } \\
\text { Approach: Paired counties on opposite } \\
\text { sides of state borders. }\end{array}$ \\
\hline $\begin{array}{l}\text { Allegretto, Dube, } \\
\text { and Reich (2011) }\end{array}$ & Near zero for teens. & $\begin{array}{l}\text { Data: Current Population Survey. } \\
\text { Approach: States compared only to those } \\
\text { in same Census division. }\end{array}$ \\
\hline $\begin{array}{l}\text { Addison et al. } \\
\text { (2013) }\end{array}$ & $\begin{array}{l}\text { Varying sign, more negative, generally insignificant for } \\
\text { restaurant workers and teens; stronger negative at } \\
\text { height of Great Recession }(-0.34) \text {. }\end{array}$ & $\begin{array}{l}\text { Data: QCEW, CPS, and American } \\
\text { Community Survey (ACS). } \\
\text { Approach: Similar methods to Dube et al. } \\
\text { (2010) and Allegretto et al. (2011) } \\
\text { restricted to 2005-10 period. }\end{array}$ \\
\hline $\begin{array}{l}\text { Gittings and } \\
\text { Schmutte (2016) }\end{array}$ & $\begin{array}{l}\text { Near zero for teens; larger negative elasticities in } \\
\text { markets with short non-employment durations ( }-0.1 \text { to } \\
-0.98 \text { ) and smaller positive elasticities in markets with } \\
\text { long non-employment durations }(0.2 \text { to } 0.46) \text {. }\end{array}$ & $\begin{array}{l}\text { Data: Quarterly Workforce Indicators } \\
\text { (QWI). } \\
\text { Approach: States compared only to those } \\
\text { in same Census division. }\end{array}$ \\
\hline Slichter (2016) & -0.04 (teens). & $\begin{array}{l}\text { Data: QWI. } \\
\text { Approach: Comparisons to bordering } \\
\text { counties and other nearby counties. }\end{array}$ \\
\hline Liu et al. (2016) & -0.17 (14-18 year-olds). & $\begin{array}{l}\text { Data: QWI. } \\
\text { Approach: Comparisons within Bureau of } \\
\text { Economic Analysis (BEA) Economic } \\
\text { Areas (EA) that cross state lines, with } \\
\text { controls for EA-specific shocks. }\end{array}$ \\
\hline \multicolumn{3}{|l|}{ Other approaches } \\
\hline Thompson (2009) & -0.3 (for teen employment share). & $\begin{array}{l}\text { Data: QWI. } \\
\text { Approach: Low-wage counties vs. higher- } \\
\text { wage counties in states. }\end{array}$ \\
\hline $\begin{array}{l}\text { Neumark et al. } \\
\text { (2014a, 2014b) }\end{array}$ & $\begin{array}{l}-0.14 /-0.15 \text { for teens, }-0.05 /-0.06 \text { for restaurant } \\
\text { workers. }\end{array}$ & $\begin{array}{l}\text { Data: QCEW and CPS. } \\
\text { Approach: States compared to data-driven } \\
\text { choice of controls (synthetic control), and } \\
\text { state panel data. }\end{array}$ \\
\hline $\begin{array}{l}\text { Baskaya and } \\
\text { Rubinstein (2015) }\end{array}$ & -0.3 to -0.5 for teens. & $\begin{array}{l}\text { Data: CPS. } \\
\text { Approach: States, using federally-induced } \\
\text { variation as instrumental variable. }\end{array}$ \\
\hline $\begin{array}{l}\text { Dube and } \\
\text { Zipperer (2015) }\end{array}$ & -0.051 (mean) and -0.058 (median) for teens. & $\begin{array}{l}\text { Data: CPS. } \\
\text { Approach: States compared to data-driven } \\
\text { choice of controls (synthetic control). }\end{array}$ \\
\hline $\begin{array}{l}\text { Clemens and } \\
\text { Wither (2016) }\end{array}$ & $\begin{array}{l}\text { Appx. }-0.97, \text { for those directly affected by minimum } \\
\text { wage increase. }\end{array}$ & $\begin{array}{l}\text { Data: Survey of Income and Program } \\
\text { Participation, CPS. } \\
\text { Approach: Targeted/affected workers } \\
\text { versus other low-wage workers in states } \\
\text { affected by federal increases }\end{array}$ \\
\hline Powell (2016) & -0.44 for teens. & $\begin{array}{l}\text { Data: CPS. } \\
\text { Approach: States compared to data-driven } \\
\text { choice of controls (synthetic controls, } \\
\text { estimated simultaneously with } \\
\text { employment effect). }\end{array}$ \\
\hline
\end{tabular}




\begin{tabular}{|l|l|l|}
\hline Authors & Employment elasticity and groups studied & Data/approach \\
\hline Totty (2017) & $\begin{array}{l}-0.01 \text { to }-0.03 \text { for restaurant workers; }-0.03 \text { to }-0.07 \\
\text { for teens. }\end{array}$ & $\begin{array}{l}\text { Data: QCEW and CPS. } \\
\text { Approach: States compared to data-driven } \\
\text { choice of controls (factor model). }\end{array}$ \\
\hline
\end{tabular}

Notes: The table reports my best attempts to identify the authors' preferred estimates reported in the papers. The Thompson estimate cannot be compared directly to other elasticity estimates because there is no population count in the data source used. The Clemens/Wither elasticity is based on a 6.6 percentage point decline (p. 27), divided by a 70.2 percent employment rate (or a 9.4 percent employment decline), divided by a $9.7 \%$ minimum wage increase (50 cents, from p. 14, divided by $\$ 5.15$ ). (These numbers are reported in a 2016 version of the study.) 
Table 2. Weights on States in Same Census Division from Synthetic Control Method, CPS Data at State by Quarter Level, 1990 - 2011:Q2

\begin{tabular}{|c|c|c|c|c|c|c|}
\hline \multirow[b]{3}{*}{ Division } & \multicolumn{3}{|c|}{ Proportion of weight on states in same division } & \multirow[b]{3}{*}{$\begin{array}{c}\text { Avg. \# } \\
\text { divisions in } \\
\text { donor pool } \\
(4)\end{array}$} & \multirow[b]{3}{*}{$\begin{array}{c}\text { Avg. \# } \\
\text { states in } \\
\text { donor pool } \\
\text { (5) }\end{array}$} & \multirow[b]{3}{*}{$\begin{array}{l}\text { Avg. \# states in } \\
\text { donor pool in } \\
\text { same division } \\
(6)\end{array}$} \\
\hline & \multicolumn{3}{|c|}{ Matching on: } & & & \\
\hline & $\begin{array}{l}\text { Log teen } \\
\text { employment- } \\
\text { to-population } \\
\text { ratio } \\
(1)\end{array}$ & $\begin{array}{c}\text { One-quarter } \\
\text { difference in log } \\
\text { teen employment- } \\
\text { to-population ratio } \\
(2)\end{array}$ & $\begin{array}{c}\text { Four-quarter } \\
\text { difference in log } \\
\text { teen employment- } \\
\text { to-population ratio } \\
\text { (3) }\end{array}$ & & & \\
\hline New England & 0.209 & 0.163 & 0.185 & 6.9 & 30.4 & 1.9 \\
\hline Middle Atlantic & 0.134 & 0.455 & 0.168 & 5.5 & 20.0 & 1.0 \\
\hline East North Central & 0.000 & 0.016 & 0.015 & 9.0 & 39.5 & 3.5 \\
\hline West North Central & 0.823 & 0.698 & 0.464 & 3.7 & 7.7 & 1.7 \\
\hline South Atlantic & 0.290 & 0.075 & 0.222 & 6.9 & 26.8 & 4.9 \\
\hline Pacific & 0.339 & 0.279 & 0.297 & 5.3 & 21.1 & 2.1 \\
\hline Aggregate & 0.323 & 0.264 & 0.251 & 6.1 & 24.0 & 2.5 \\
\hline
\end{tabular}

Notes: Results are reported for the 50 unique minimum wage treatments (out of a total of 129 increases based on criteria described in the text) for which there is at least one potential donor state from the same Census division. The numbers in columns (4)-(6) refer to the matching on residuals or the log teen employment-to-population ratio. There are somewhat fewer minimum wage treatments when matching on the one- or four-quarter differences in the employment-to-population ratio because the earliest lags are not available at the beginning of the sample period. The aggregate row reports the means across all treatment units.

Source: Neumark et al. (2014a). 